Original Research Paper

\title{
Contributions to the Stirling Engine Study
}

\author{
Florian Ion Tiberiu Petrescu \\ ARoTMM-IFToMM, Bucharest Polytechnic University, Bucharest, (CE), Romania
}

Article history

Received: 22-10-2018

Revised: 08-11-2018

Accepted: 20-11-2018

Email: scipub02@gmail.com

\begin{abstract}
In the process of transforming thermal energy into mechanical work, among the known thermal machines, the Stirling engine is the one that can achieve the highest yield (theoretically up to the maximum yield of the Carnot cycle), although in practice it is reduced by the properties of gas and materials used such as friction coefficient, thermal conductivity, melting point, breaking strength, plastic deformation, etc. This type of engine can operate on the basis of a heat source irrespective of its quality, whether it is solar, chemical, nuclear, biological, etc. Unlike internal combustion engines, the Stirling engines can be economical, quieter, safer and less maintenance-free. They are preferred in specific applications where these advantages are reaped, especially if the main objective is not to minimize investment costs per unit of power $(\mathrm{RON} / \mathrm{kW})$ but to those per unit of energy (RON $/ \mathrm{kWh}$ ). Compared to internal combustion engines of a given power, the Stirling engines require higher capital expenditure, are larger and heavier, for which reason, viewed from this point of view, this technology is uncompetitive. For some applications, however, a sound analysis of the earnings-to-revenue ratio may favor Stirling engines versus internal combustion engines. More recently, Stirling's benefits have become visible compared to rising energy costs, lack of energy resources and environmental issues such as climate change. Increasing interest in Stirling engine technology has spurred research and development in this area lately. Uses a range of water pumping to astronautics and power generation based on rich sources of energy incompatible with internal combustion engines such as solar energy, or plant and animal scraps. In this respect, the fourstroke four-stroke engine type Stirling is the most advantageous, being driven continuously from the piston. For this reason, it has a stranger load feature, which is said to be inappropriate for car use (the more crankshaft driven crankshaft, although having less mechanical efficiency, have a much longer stable and respond quickly to changes in the working regimes required by a vehicle, especially due to the large inertial help of the shaft, plus the steering wheel, which are more "nerve-wise" and therefore more dynamic). This can, however, be easily corrected in Stirling engines by using multiple cylinders simultaneously, trapped on the same shaft (multicylinder Stirling), the shaft having a high inertia, which can be further enhanced by -a wheel. Even though the cylinders work most of the time in motor regimes, they are permanently connected to the output shaft which must have a very high inertia in construction, the movement at the output of the motor being picked from the shaft.
\end{abstract}

Keywords: Stirling Engine, Thermal Machines, Multi-Cylinder Stirling, Thermal Motors, Efficiency, Yield, Dynamic Kinematics

\section{Introduction}

The engine is a machine that converts some form of energy into mechanical energy.
The following types of engines are distinguished:

Electric, magnetic, electromagnetic, sonic, pneumatic, hydraulic, wind, geothermal, solar, nuclear, reaction (Coanda, ionic, ionic, electromagnetic, plasma, photonic). 
Being the oldest, most widely used and most common motors, thermal motors (which convert thermal energy into mechanical energy) can also be classified into two broad categories: External combustion engines and internal combustion engines (Petrescu and Petrescu, 2016a; 2016b; 2016c, 2013a; 2013b, 2012a; 2012b; 2012c, 2011; 2005a; 2005b; 2005c; 2005d; 2005e, 2003, 2002a; 2002b, 2000a; 2000b, 1997a; 1997b; 1997c, 1995a; 1995b, Petrescu, 2015a; 2015b; 2012; 2011; Petrescu et al., 2017a; 2017b; 2017c; 2017d; 2017e; 2017f; 2017g; 2017h; 2017i; 2017j; 2017k; 2017l; 2017m; 2017n; 2017o; 2017p; 2017q; 2017r; 2017s; $2017 \mathrm{t} ; 2017 \mathrm{u} ; 2017 \mathrm{v} ; 2017 \mathrm{w} ; 2017 \mathrm{x} ; 2017 \mathrm{y} ; 2017 \mathrm{z}$; 2017aa; 2017ab; 2017ac; 2017ad; 2017ae; 2016; 2009).

Among the most famous external combustion engines we mention: Steam engines and Stirling engines.

The category of internal combustion engines being the most common, most used and most important, includes several subcategories, of which we will try to list a few:

The Lenoir engine, the Otto four-stroke engine, the Diesel engine, the Wankel rotary engine, the Atkinson rotary engine, the biodisel engines, the hydrogen engines and so on.

The most common external combustion engines are steam engines. Although initially used as a naval engine, the emergence and development of steam engines (as well as the first cam mechanism) are closely related to the emergence and development of tissue wounds (automatic tissue machines).

In 1719, in England, some John Kay opens in a five-story building a filth. With a staff of over 300 women and children, this would be the world's first factory. He also becomes famous by inventing the flying sail, which makes the tissue much faster. But the machines were still manually operated. It was not until 1750 that the textile industry was to be revolutionized by the widespread application of this invention. Initially the weavers opposed it, destroying flying sails and banishing the inventor (Petrescu and Petrescu, 2012a).

By 1760 the wars of the weaving and the first factories appeared in the modern sense of the word. It took the first engines. For more than a century, Italian Giovanni Branca (1571-1645) proposed the use of steam for the operation of turbines (the first modern steam engine with steam combustion built by the engineer and Italian architect Giovanni BRANCA was a steam turbine).

Subsequent experiments were not satisfying. In France and England, inventors such as Denis Papin (1647-1712, French mathematician and inventor, pioneer of steam engines, whose first steam engine was built in 1679) or the Worcester Marquis (1603-1667), with us and new ideas.
At the end of the seventeenth century, Thomas Savery (1650-1715) had already built the "friend of the miner", a steam engine (patented, with no mechanism, no moving parts, he was a sort of compressor, a pressure bottle pushing the water out of the cylinder through a hole when it was open) that puts a pump into the water to remove the water from the galleries, or was mounted on the fire-fighting vehicles to pump the water to fire.

Thomas Newcomen (1664-1729) built the commercial steamer version and engineer James Watt (1736-1819) develops and adapts a speed regulator that improves the net steam engine (Petrescu and Petrescu, 2012a).

J. Watt - 1763 has greatly improved the machines achieved so far by reducing the heat and energy losses in coal-fired steam boilers (Fig. 1 shows James Watt's original steam engine, an invention that would change the face of the world, designed in 1769 and improved in 1774). The steam engine invented by Watt later benefited from three other French inventions: $M$. Seguin's 1817 tubing boiler, E. Bourdon's manometer - 1849 and T. Gifford's injector - 1858 (Petrescu and Petrescu, 2012a).

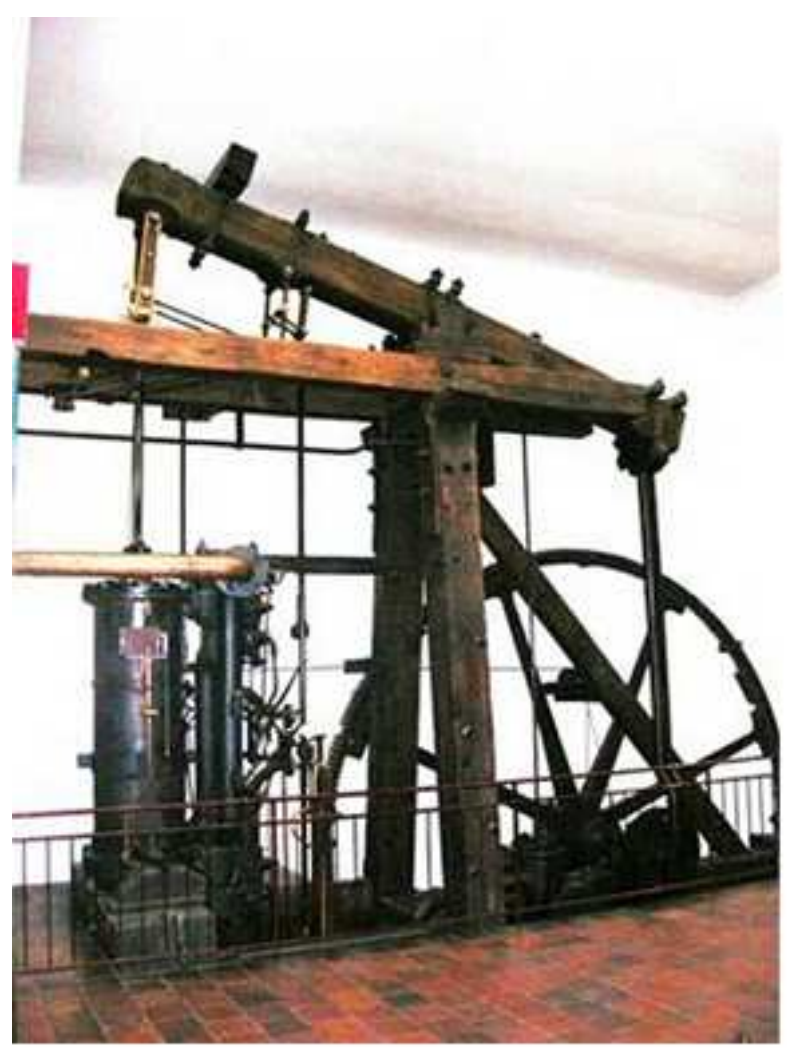

Fig. 1: James Watt's original steam engine, an invention that would change the face of the world, designed in 1769 and improved in 1774 
The steam engine has allowed factories to be located not only in the vicinity of watercourses but also where their products were needed - shopping centers, cities (The first practical application was in me, followed by the cotton, beer, etc. industry. Britain, in the west of the continent and then in the 19th-20th centuries around the world).

James Watt was born in Greenock, Scotland. He completed his studies in London, England and began working as a mathematical tool maker (1754). He returned to his native lands in Glasgow, Scotland. He was the manufacturer of mathematical tools used by the University of Glasgow (Petrescu and Petrescu, 2012a).

Here he was given the opportunity (destiny) to repair a steam car, which helped him to improve it; so the "steam condensing chamber" (1769) and the "steam machine speed controller" (1788) appeared. In the machine invented in 1769 , the steam passed into a separate room for condensation.

Since the cylinder was not heated and cooled alternately, the heat loss of the machine was relatively low. Also, Watt's car was faster, because more steam could be allowed in the cylinder once the piston had returned to its original position. This and other improvements designed by Watt have made the steam machine can be used in a wide range of applications (Petrescu and Petrescu, 2012a).

He later moved to England in Birmingham. Here he enters a club, the "Lunar Society," which - despite its deceptive name - was in fact a scientific club made up of inventors. Many of his original works are at the Birmingham Cultural Library (Birmingham Central Library).

James Watt, along with a British industrialist, Matthew Boulton, succeeded in creating an enterprise for the manufacture of what was called Watt's Improved Steam Machine (1774). Here, along with another Scottish inventor William Murdoch, he will realize a rotary motion conversion gear (1781). Subsequently, he made a double-action car (1782).

Its greatest achievement is considered to be the patenting of the steam locomotive in 1784 (Fig. 2). As a matter of fact, in that year, in 1784, transport was born on the railway (Petrescu and Petrescu, 2012a).

Together with Mathiew Boulton, Scottish engineer James Watt builds the first steam-powered steam engines (Fig. 3) and in less than half a century, the wind that fed over 3,000 years ago, propulsion power at sea now only blooms pleasure boats.

Interestingly, Watt's first steam engine (the first version of 1769) was taken over by the French engineer Nicolas Joseph Cugnot and originally adapted (Fig. 4) for use in the very same year (1769) when building the first vehicle, originally intended for military and armament transport, but also heavy towing, heavy cannon. The maximum speed of this first vehicle (improved version) at maximum load (four in-vehicle vehicles plus towed heavy tolls of no more than $4 \mathrm{t}$ ) was $5 \mathrm{~km}$ per hour and at a half load it touched dry roads $8.5 \mathrm{~km} / \mathrm{h}$.

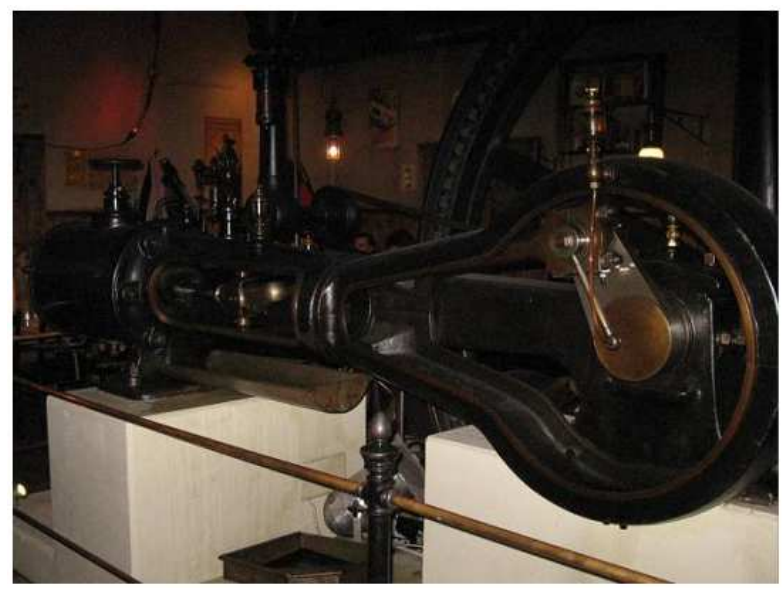

Fig. 2: The James Watt's patenting of the steam locomotive in 1784

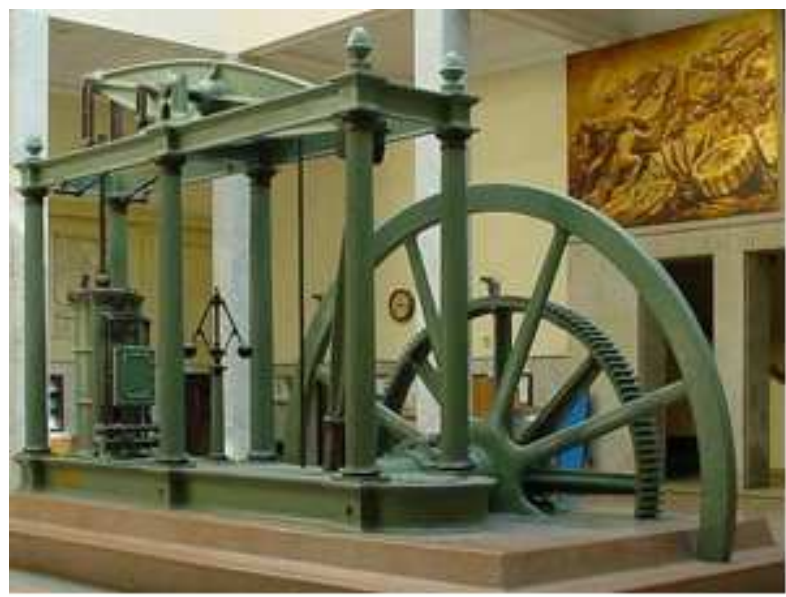

Fig. 3: First steam-powered engines

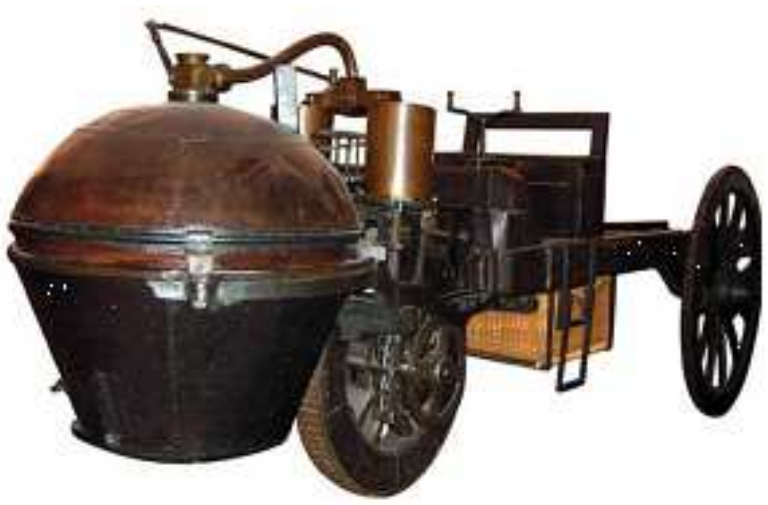

Fig. 4: Joseph Cugnot's (1769) first vehicle 


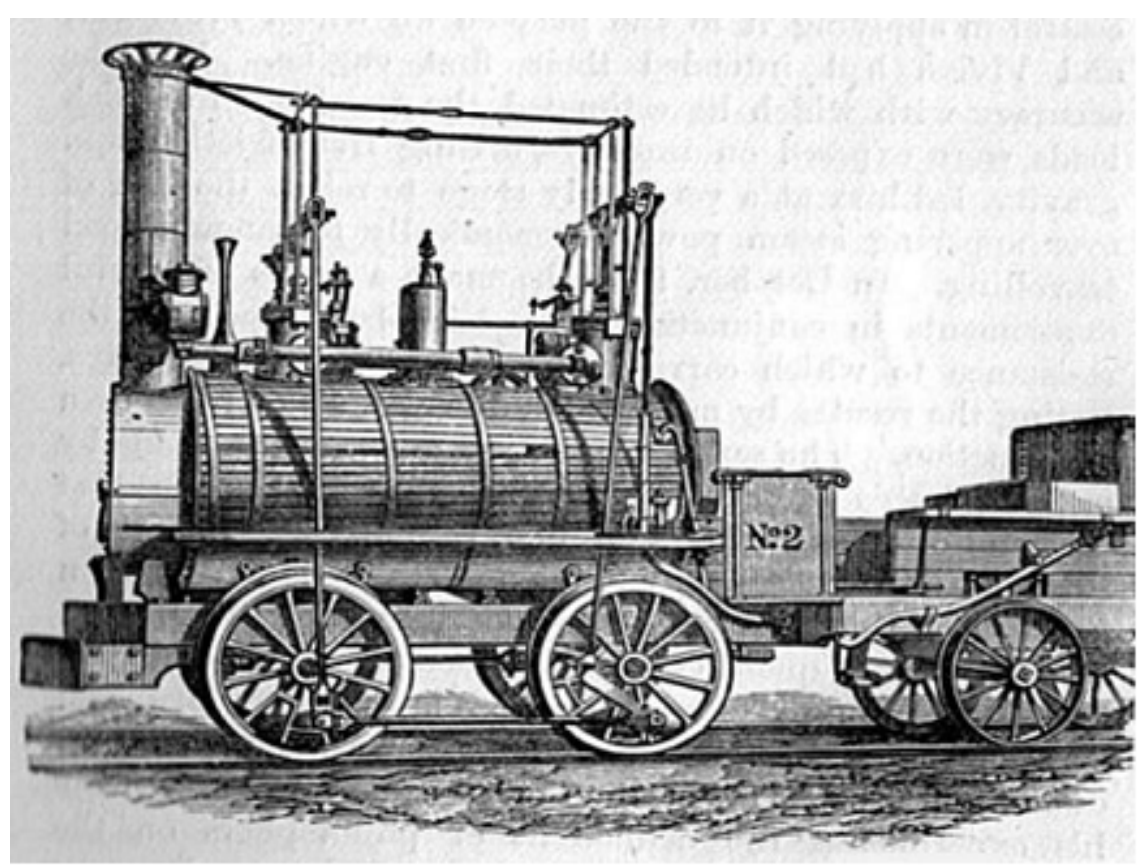

Fig. 5: The first steam locomotive, built on the railroad, was built based on Watt's model, by British engineer George Stephenson in 1814

The first steam locomotive, built on the railroad, was built based on Watt's model, by British engineer George Stephenson (1781-1848), only in 1814 (Fig. 5), (Petrescu and Petrescu, 2012a).

Robert Fulton (who is incorrectly assigned to construct and construct the first motorized vessels 18031807) can be credited to have been the author of the plans and the actual builder (1798) of the first functional submarine, commissioned by Napoleon Bonaparte, named Nautilus, in 1800 in France by Fulton himself with three mechanics, sinking to the depth of 25 feet (Petrescu and Petrescu, 2012a).

In 1785 came into operation, the first steam driven steamer, followed quickly by a few dozen.

The development of ship engines, trains, cars and automated weaving engines has led to the development of the European and American steel industry (and later also the world).

It is remarkable that the first motorized vehicle (equipped with a steam engine) was a car, followed by a submarine, various ships and then trains. Steam engines have been used (and are still used today) as stationary thermal motors in plants, acting on pumps, reducers and machine tools.

One of the oldest steam engines used (including locomotives), first adapted by Watt, is the "steam engine with three expansion tanks" (Fig. 6). Not only have some engines been kept, but they have begun to be reused due to the low pollution they produce and good performance. Their main disadvantage, for which they almost disappeared in the "black oil era" (dominated by oil), was the lack of compaction. But their advantage is that, as they have started, they can use various fuels, which can be useful to reduce the consumption of petroleum products and remain alive even when oil falls to its disappearance (Petrescu and Petrescu, 2012a).

As external combustion engines, they can be adapted to use various fuels such as biofuels, alcohols, hydrogen, vegetable oils, seeds, soybeans, peanuts, or extracts from various plants, or biofuels extracted from seaweed and oceanic, etc. We no longer have to feed these "noble horsepower" only with poor quality coal and then say that these engines smoke "smelly smoke" (coal was a polluting fuel of the planet).

Let's imagine these modernized "grandparents and grandparents", imagine these "naftaline" engines, beautifully polished, redesigned on modern principles, reshaped to modern (compacted) fuels, made of modern materials (ceramics, super metals, special alloys, etc.) and we think that they can become a real alternative transport and motor source even when oil is no longer alongside modern electric motors with internal combustion engines on hydrogen together with the other types of external combustion thermal engine (Stirling).

We can still imagine the heated water to the vapor state with the help of modern electrical induction, induction, microwave, or various modern means, using the solar electric power, captured and stored in modern accumulators. The result... strong, robust, dynamic, compact, non-smokeless, oil-free, smoke-free thermal motors, working at high efficiency (not only mechanical but also thermal). 


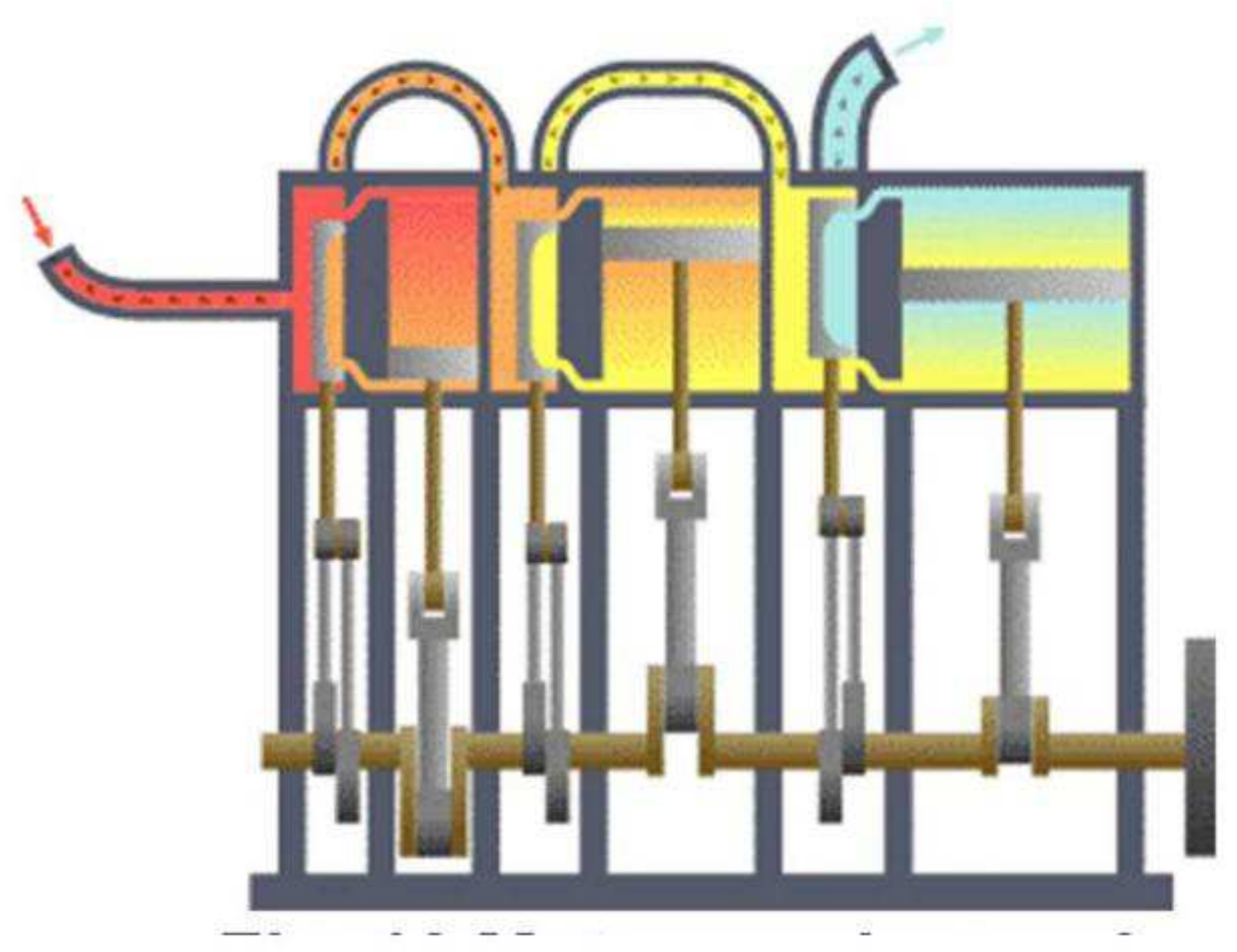

Fig. 6: The oldest steam engines used (including locomotives), first adapted by Watt, is the "steam engine with three expansion tanks"

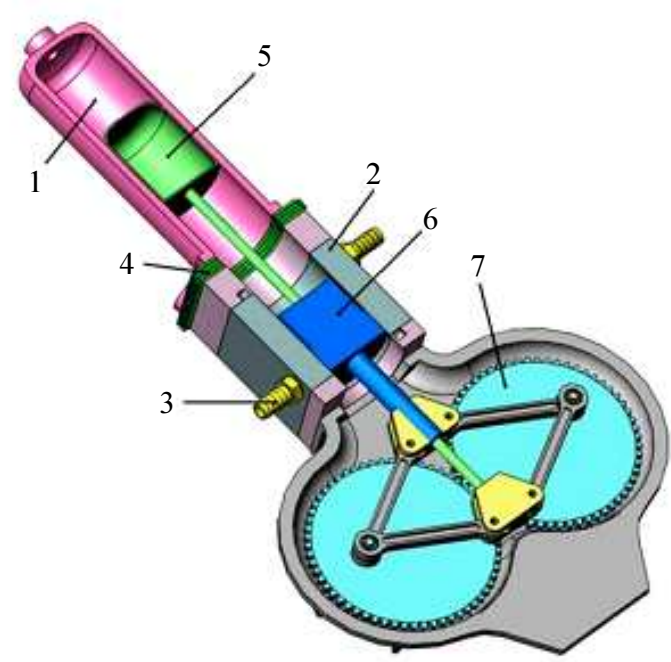

Fig. 7: A section of a Beta Stirling type engine with a rombic bead mechanism

Also in this context are the modern Stirling engines.

Figure 7 shows a section of a Beta Stirling type engine with a rombic bead mechanism (Petrescu and Petrescu, 2012a).
[1 - the hot wall of the cylinder, 2 (dark gray) - the cold wall of the cylinder (with 3 cooling joints), 4 - the thermal insulation separating the ends of the two cylinders, 5 - the discharge piston, 7 -volts; Unrepresented: External power supply and cooling radiators. In this drawing the discharge piston is used without a regenerator.]

A Beta Stirling engine has a single cylinder in which a working piston and a discharge piston are mounted on the same shaft. The discharge piston is not leak-tight and does not serve to extract mechanical work from the expanding gas, with only the role of operating the working gas between the hot and cold heat exchanger. When working gas is pushed to the hot end of the cylinder, it expands and pushes the plunger. When pushed to the cold end, the inertia moment of the engine, usually increased by a steering wheel, shakes the working piston in the opposite direction to compress the gas. Unlike the Alfa type, the technical problems related to the hot piston sealing rings are avoided in this case. The four operating times of the Beta Stirling engine can be seen in Fig. 8 (Petrescu and Petrescu, 2012a). An Alfa Stirling model can be seen in Fig. 9. 
Bild 1:

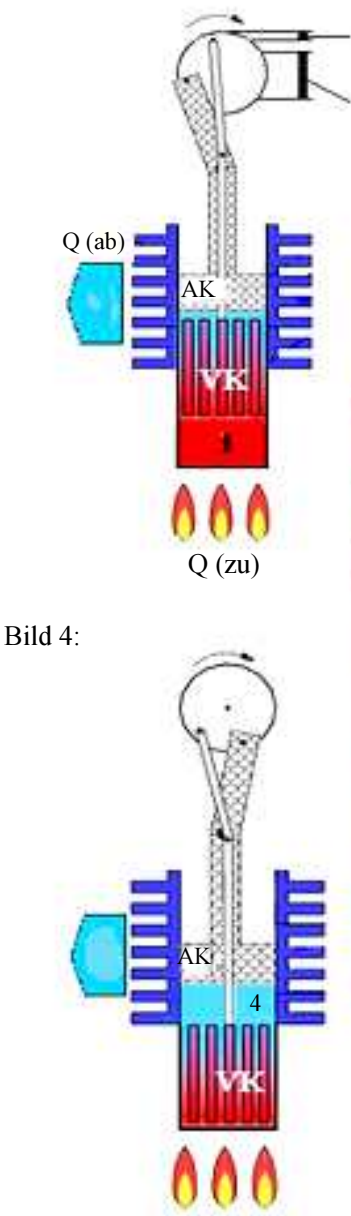

AK Arbeitskolben

VK Verdrãngerkolben (Regenerator)

$\mathrm{T}_{\mathrm{u}}$ untere Prozessteinperatur

$\mathrm{T}_{\mathrm{o}}$ obere Prozessteinperatur

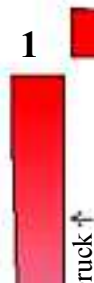

Bild 2:

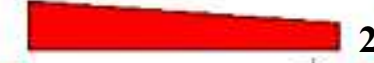

2

Isotherme $\mathrm{T}_{0}$, Druck
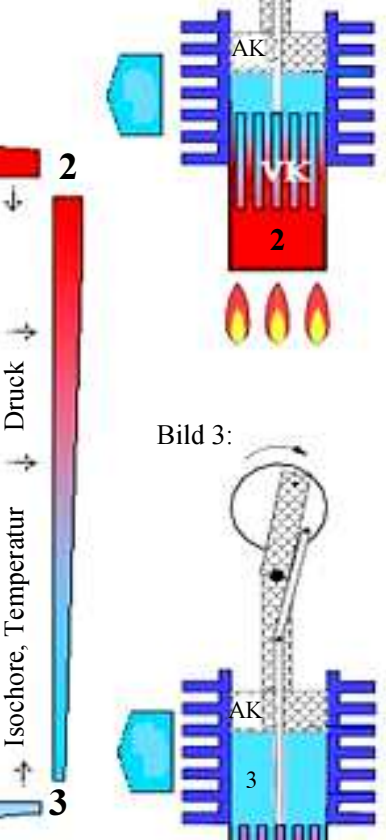

Schwungrad

川11

2
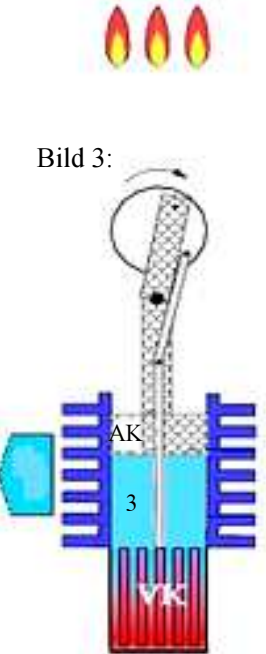

OAO

Q (zu) Wãrmezufuhr von außen Q (ab) Wãrmeabfufuhr/Kühlwarme

1,2,3,4 Aufenthaltsort eines Gasteilchens entsprechend

den Eckpunkten im p-V und T-s-Diagramm

Fig. 8: The four operating times of the Beta Stirling engine

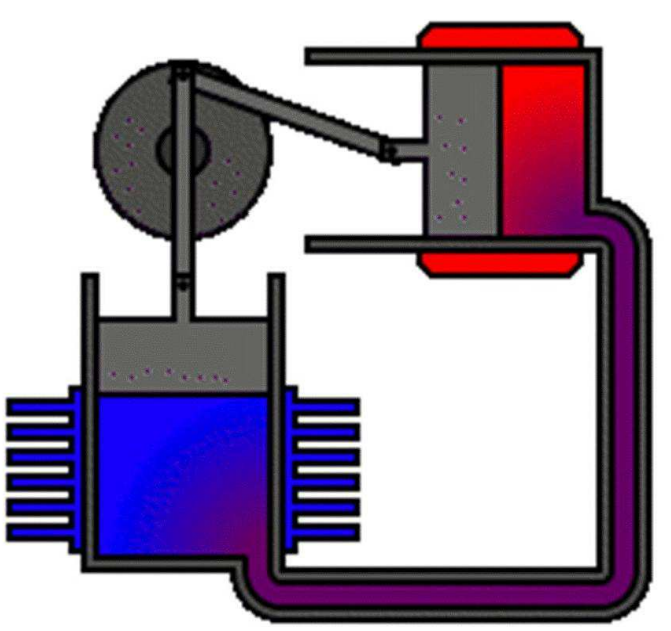

Fig. 9: An Alfa Stirling model
An Alfa Stirling engine contains two working pistons, one hot and one cold, located separately in one cylinder. The cylinder of the hot piston is located inside the high temperature heat exchanger and the cold piston in the low temperature heat exchanger. This type of motor has a very high literal power but has technical difficulties due to the very high temperatures in the area of the hot piston and its sealing. The Alfa Stirling engine can be described in four ways:

- Time 1: Most of the working gas is in contact with the wall of the hot cylinder; as a result, heats up his volume and pushes the piston towards the end of the cylinder. The dilatation continues also in the cold cylinder whose piston has a $90^{\circ}$ downshift 
motion relative to the piston of the hot cylinder, with further mechanical extraction (Petrescu and Petrescu, 2012a)

- Time 2: The working gas has reached the maximum volume. The piston in the hot cylinder begins to push most of the gas into the cold cylinder where it loses its accumulated temperature and the pressure drops

- Time 3: Almost all the amount of gas is in the cold cylinder and continuous cooling. The cold piston, driven by the inertia moment of the flywheel or another pair of pistons on the same shaft, compresses the gas

- Time 4: The gas reaches the minimum volume and the piston in the hot cylinder will allow the vehicle to travel to this cylinder where it will be heated again and the mechanical workout to the working piston will start

The Gamma Stirling model can be seen in Fig. 10.

A Stirling Range Engine is a Stirling Beta in which the working piston is mounted in a separate cylinder adjacent to the discharge cylinder but is connected to the same steering wheel. The gas in the two cylinders circulates freely between them. This variant produces a lower compression ratio but is constructively simpler and is often used in Stirling with several cylinders (Fig. 11 shows a 4-cylinder alpha-Stirling engine with high efficiency, power, speed and torque being high and the action is done by simultaneously burning four candles).

"Stirling engine enthusiasts of this kind must make a reserve of candles!" (Petrescu and Petrescu, 2012a).

Gamma Stirling model Engine Operation Stirling Range (Petrescu and Petrescu, 2012a):

- Time 1: During this phase the working piston performs a minimum stroke, the total volume is minimal. Instead, the discharge spout performs a long stroke and the working gas heats up

- Time 2: The discharge piston has a short stroke, while the piston performs more than $70 \%$ of its total stroke. It generates mechanical energy

- Time 3: The discharge piston performs most of its run: The gas is cooled. The piston has a short stroke

- Time 4: The discharge piston remains at the top of the cylinder: The gas is completely cooled. Instead, the plunger travels most of his stroke: Compresses the gas and gives up mechanical work for that purpose

A special field is Stirling "free piston" engines, including those with liquid piston and diaphragm (Fig. 12), (Petrescu and Petrescu, 2012a).

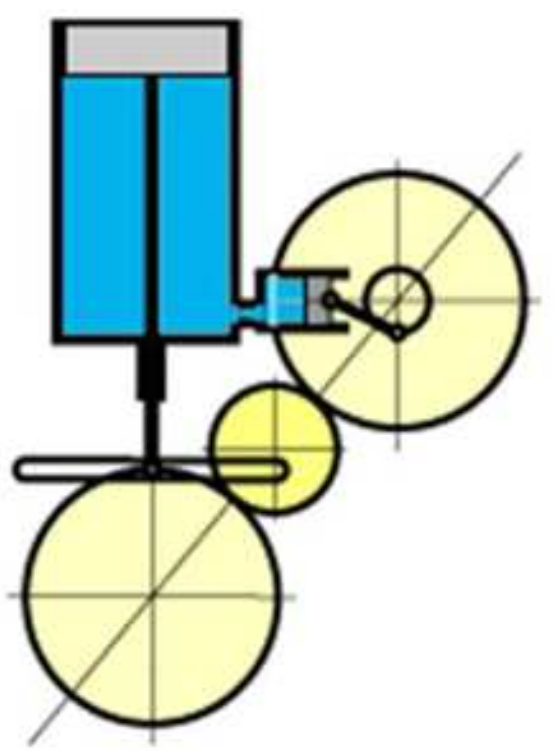

Fig. 10: The Gamma Stirling model

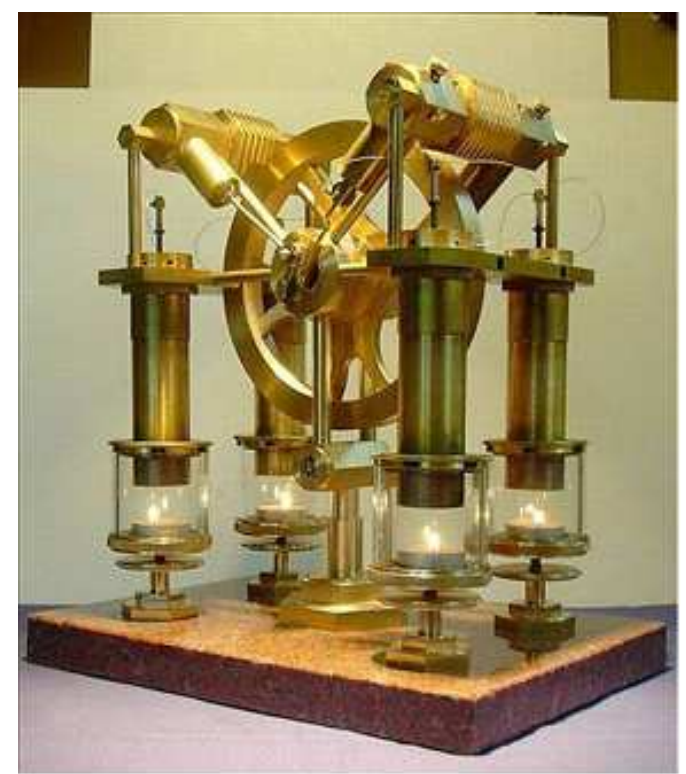

Fig. 11: A 4-cylinder alpha-Stirling engine with high efficiency, power, speed and torque being high and the action is done by simultaneously burning four candles

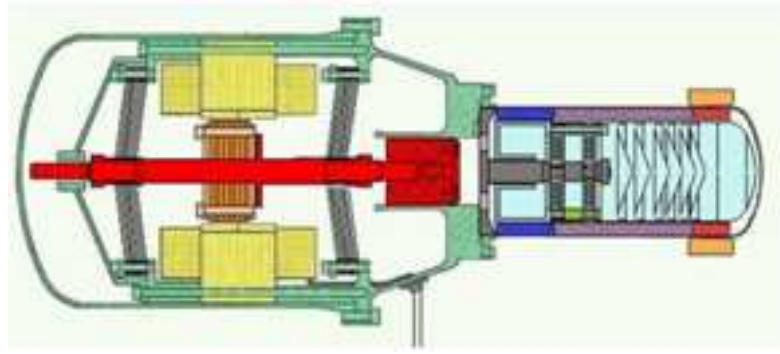

Fig. 12: Stirling "free piston" engines, including those with liquid piston and diaphragm 
In 2010, more than 800 million vehicles circulate across the planet (Frățilă et al., 2011; Pelecudi, 1967; Antonescu, 2000; Comănescu et al., 2010; Aversa et al., 2016a; 2016b; 2016c; 2016d; 2017a; 2017b; 2017c; 2017d; 2017e; Mirsayar et al., 2017; Cao et al., 2013; Dong et al., 2013; De Melo et al., 2012; Garcia et al., 2007; Garcia-Murillo et al., 2013; He et al., 2013; Lee, 2013; Lin et al., 2013; Liu et al., 2013; Padula and Perdereau, 2013; Perumaal and Jawahar, 2013; Petrescu and Petrescu, 1995a; 1995b; 1997a; 1997b; 1997c; 2000a; 2000b; 2002a; 2002b; 2003; 2005a; 2005b; 2005c; 2005d; 2005e, 2016a; 2016b; 2016c; 2016d; 2016e; 2013; 2012a; 2012b; 2011; Petrescu et al., 2009; 2016a; 2016b; 2016c; 2016d; 2016e; 2017a; 2017b; $2017 \mathrm{c} ; 2017 \mathrm{~d} ; 2017 \mathrm{e} ; 2017 \mathrm{f} ; 2017 \mathrm{~g} ; 2017 \mathrm{~h} ; 2017 \mathrm{i}$; 2017j; 2017k; 2017l; 2017m; 2017n; 2017o; 2017p; 2017q; 2017r; 2017s; 2017t; 2017u; 2017v; 2017w; 2017x; 2017y; 2017z; 2017aa; 2017ab; 2017ac; 2017ad; 2017ae; Petrescu and Calautit, 2016a; 2016b; Reddy et al., 2012; Tabaković et al., 2013; Tang et al., 2013; Tong et al., 2013; Wang et al., 2013; Wen et al., 2012; Antonescu and Petrescu, 1985; 1989; Antonescu et al., 1985a; 1985b; 1986; 1987; 1988; 1994; 1997; 2000a; 2000b; 2001; List the first flights, From Wikipedia; Chen and Patton, 1999; Fernandez et al., 2005; Fonod et al., 2015; Lu et al, 2015; 2016; Murray et al., 2010; Palumbo et al., 2012; Patre and Joshi, 2011; Sevil and Dogan, 2015; Sun and Joshi, 2009; Crickmore, 1997; Donald, 2003; Goodall, 2003; Graham, 2002; Jenkins, 2001; Landis and Dennis, 2005; Clément, Wikipedia; Cayley, Wikipedia; Coandă, Wikipedia; Gunston, 2010; Laming, 2000; Norris, 2010; Goddard, 1916; Kaufman, 1959; Oberth, 1955; Cataldo, 2006; Gruener, 2006; Sherson et al., 2006; Williams, 1995; Venkataraman, 1992; Oppenheimer and Volkoff, 1939; Michell, 1784; Droste, 1915; Finkelstein, 1958; Gorder, 2015; Hewish, 1970; Wiederrich and Roth, 1974; Fawcett and Fawcett, 1974; Jones and Reeve, 1974; Tesar and Matthew, 1974; Sava 1970; 1971; Koster, 1974).

\section{Materials and Methods}

In the process of transforming thermal energy into mechanical work, among the known thermal machines, the Stirling engine is the one that can achieve the highest yield (theoretically up to the maximum yield of the Carnot cycle), although in practice it is reduced by the properties of gas and materials used such as friction coefficient, thermal conductivity, melting point, breaking strength, plastic deformation, etc. This type of engine can operate on the basis of a heat source irrespective of its quality, whether it is solar, chemical, nuclear, biological, etc (Aversa et al., 2017a; 2017b, 2016a; 2016b; 2016c; 2016d; 2016e; 2016f; Mirsayar et al., 2017; Petrescu et al., 2017).
Unlike internal combustion engines, the Stirling engines can be economical, quieter, safer and less maintenance-free. They are preferred in specific applications where these advantages are reaped, especially if the main objective is not to minimize investment costs per unit of power $(\mathrm{RON} / \mathrm{kW})$ but to those per unit of energy (RON/kWh). Compared to internal combustion engines of a given power, the Stirling engines require higher capital expenditure, are larger and heavier, for which reason, viewed from this point of view, this technology is uncompetitive. For some applications, however, a sound analysis of the earnings-to-revenue ratio may favor Stirling engines versus internal combustion engines (Petrescu and Petrescu, 2012a).

More recently, Stirling's benefits have become visible compared to rising energy costs, lack of energy resources and environmental issues such as climate change. Increasing interest in Stirling engine technology has spurred research and development in this area lately. Uses range from water pumping to astronautics and power generation based on rich sources of energy incompatible with internal combustion engines such as solar energy, or plant and animal scraps.

Another feature of the Stirling engines is their reversibility. Mechanically operated, they can act as heat pumps. Tests were conducted using wind energy to drive a Stirling cycle heat pump to heat and condition air for dwelling in cold weather.

Stirling's aircar was invented by clergyman Robert Stirling and patented by him in 1816 . The date when the simplified name of the Stirling engine was established is not known, be estimated in the mid-twentieth century when Philips began research on non-airborne fluids (MP1002CA is still referred to as the 'air engine' in the operating instructions). The main theme of the patent referred to a heat exchanger that Stirling called it "economizer" because it can contribute to saving fuel in various applications. The patent thus described in detail the use of a form of economiser in an air car, which is now known as a regenerator. A Stirling engine was used in a stone quarry for water pumping in 1818. Subsequent patents by Robert Stirling and his brother, engineer James Stirling, concerned various improvements to the original car's construction, including raising internal pressure which led to a significant increase in power so that in 1845 all Dundee steel melting machines could be trained (Petrescu and Petrescu, 2012a).

In addition to saving fuel, the inventors also envisaged creating a safer engine than the steam engine, at which time the boiler exploded slightly (due to poor quality materials and various workshop technologies used at that time), often causing accidents and even loss of life.

However, obtaining a much higher Stirling engine yield, possibly by providing very high temperatures, has long been limited by the quality of the materials available at that time and the few ones built have had a reduced lifetime. 
The engine's hot engine faults were more frequent than could be expected, but with less disastrous consequences than the boom of a steam car.

Though it eventually lost steam competition with regard to the machinery drive, at the end of the nineteenth and early twentieth centuries, a large number of Stirling hot air engines (the difference between the two types is blurred if in many of them the generator is doubtful or lacking in efficiency), finding its use everywhere where medium or small but reliable power is needed, most often in pumping water. They were operating at low temperatures, so they did not demand too much the available materials, so they became quite ineffective, the advantages of steam machines being simple operation being handled by domestic personnel and the elimination of the danger of possible dangerous explosions. Over time, their role has been taken over by electric motors or internal combustion engines of smaller size, so that in the late 1930s the Stirling engine fell into oblivion, being just a technical curiosity represented by a few toys and ventilation systems. Meanwhile, Philips, the Dutch electric and electronic component company, has begun research on this type of engine. In an attempt to expand the market for its radio equipment in areas where there is no electricity grid and the battery life of short battery life was uncertain, the company's management concluded that a low power portable generator was needed, a group of engineers from his Eindhoven laboratories with research. Studying different older and newer drive motors, they were rejected for one reason or another until the choice fell on the Stirling engine. Silently built and nonselective to the heat source (cheap and available light bulb) the Stirling engine seemed to offer real possibilities. Encouraged by their first experimental engine that produced 16 watts of power on a shaft with a $30 \mathrm{~mm}$ diameter cylinder and a $25 \mathrm{~mm}$ stroke, they started a development program.

Amazingly, the work continued during World War II, so that at the end of the 1940s the Type 10 engine was finite enough to be handed over to the Johan de Witt branch in Dordrecht for serial production within a equipment for generating electricity according to the initial plan. The project was developed with prototypes $102 \mathrm{~A}, \mathrm{~B}$ and $\mathrm{C}$, reaching a power of $200 \mathrm{~W}$ (power) on a $55 \mathrm{~mm}$ diameter cylinder and a stroke of $27 \mathrm{~mm}$ on the MP1002CA (Petrescu and Petrescu, 2012a).

The production of the first batch began in 1951, but it became clear that it could not be produced at an acceptable price on the market, which added to the appearance of transistor radio appliances that had a much lower consumption (going on batteries or miniaculators) what made the initial reason for development disappear. Although the MP1002CA was a dead line, it is the start of the new era of Stirling engine development (in real terms it was a second missed start of the Stirling engine).
Thanks to the money invested and the finalized research, Philips developed the Stirling engine for a wide range of applications, but commercial success had only the Stirling engine in reverse mode used in the cold technique. Actually used backwards, it is no longer a Stirling engine but a heat product machine (as an internal combustion engine used inversely becomes a simple compressor, a pump, etc.).

However (Philips specialists) have obtained a number of patents and have accumulated a great deal of knowledge about Stirling engine technology, which was later sold as a license to other companies (Petrescu and Petrescu, 2012a).

Because the Stirling engine cycle is closed, it contains a determined amount of gas called "working fluid," most of which air, hydrogen or helium. In normal operation, the engine is sealed and gas is not exchanged inside.

Its great advantage over other types of motors is that no valves are required (it does not require one or more distribution mechanisms, which, for Otto or Diesel engines, take from 10 to $25 \%$ of the engine power, produce vibrations and noises in operation, increase the final gauge of the engine, often produce characteristic noise, higher in Diesel engines, known by specialists as beatings, or tangled by tachets, although it is due more to the cultivating mechanism; the distribution mechanisms, although built solidly, all have high elasticity in their kinematic chain, which causes large deformations in operation, making dynamic operation suffer much).

The gas exchange of internal combustion engines, via valves or windows, produces additional power losses, additional vibrations and noise and higher emissions, with the Stirling engine being superior.

Even the lack of these gas exchanges with the external environment, ensures Stirling engines a higher efficiency, a much reduced pollution, a much lower fire or explosion hazard, compared to internal combustion or steam combustion engines and a much stronger seal that enables them to operate more securely even in toxic, chemical, nuclear, marine, underwater, wet, flammable, cosmic, unknown, unsafe environments (Petrescu and Petrescu, 2012a).

Stirling's engine, similar to other thermal machines, goes through a cycle of 4 transformations (times): Heating, re-cooling, cooling and compression. The cycle occurs by moving the gas back and forth between the hot and cold heat exchangers.

The hot heat exchanger is in contact with an external heat source, for example a fuel burner and the cold heat exchanger is connected to an external radiator, for example an air heater. A change in gas temperature results in a change in pressure, while the piston movement contributes to the compression and alternate expansion of the gas.

The behavior of the working fluid is in accordance with perfect gas laws that describe the relationship 
between pressure, temperature and volume. When the gas is in a closed space, heating will produce a pressure increase that will act on the working piston causing it to move. When cooling the gas, the pressure drops, so it will take less mechanical work to compress it when the piston moves in the opposite direction, resulting in a surplus of mechanical energy (Petrescu and Petrescu, 2012a).

Many high-performance Stirling engines are pressurized, i.e. the average indoor pressure is higher than the atmospheric pressure. Thus the mass of the working fluid is higher, as a result of the amount of caloric energy transmitted, so the engine power will be higher. Increasing pressure also causes other changes such as increasing the capacity of heat exchangers as well as regenerator. This in turn can increase unused spaces as well as hydrodynamic resistance with negative effect on developed power. The construction of the Stirling engine is thus a problem of engineering optimization of several contradictory requirements.

Air pressure experiments were the ones that led Philips to move from air to other gas as a working fluid. At high temperatures, oxygen in the air tended to react with engine lubricants, which were removed from the sealing segments, clogging the heat exchangers and even presenting an explosion hazard. Later, it has been found that certain gases such as hydrogen and helium have other advantages over the air.

If one end of the cylinder is open, the operation is slightly different. When the closed volume between the piston and the cylinder heats up, a dilation occurs in the heated part, resulting in a pressure increase, which results in the piston moving. Upon reaching the cold surface, the volume of the gas is reduced resulting in pressure drop below atmospheric pressure and thus the piston movement is reversed.

In conclusion, the Stirling engine uses the temperature difference between the two hot and the cold zones to create a gas expansion-contraction cycle of a given mass gas inside a machine to convert thermal energy into mechanical work. The larger the difference between the temperatures of the two areas, the higher the cycle yield (Petrescu and Petrescu, 2012a).

Powerful stationary or mobile generators (Fig. 13) are built today using the Stirling engines, which operate an electric generator, thus obtaining heat and electricity in isolated places, hospitals, factories, hotels, institutions, etc., whether isolated or in the event of a power failure in certain special situations (incidents, earthquakes, storms, floods, power grid failure or transformer failure, etc.).

Small experimental engines (Fig. 14) have been built to operate at low temperature differences of up to $7^{\circ} \mathrm{C}$ that occur, for example, between the palm of the hand and the environment or between room temperature and ice melting temperature (Petrescu and Petrescu, 2012a).

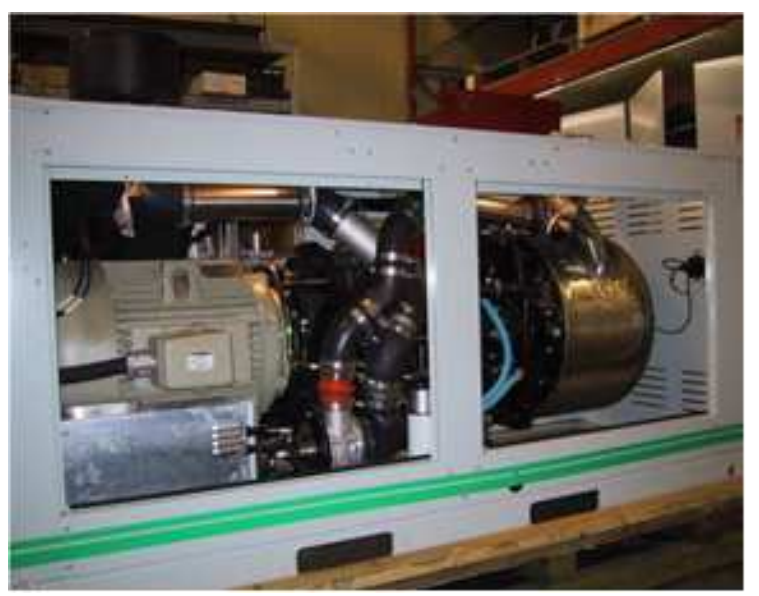

Fig. 13: Powerful stationary or mobile generators

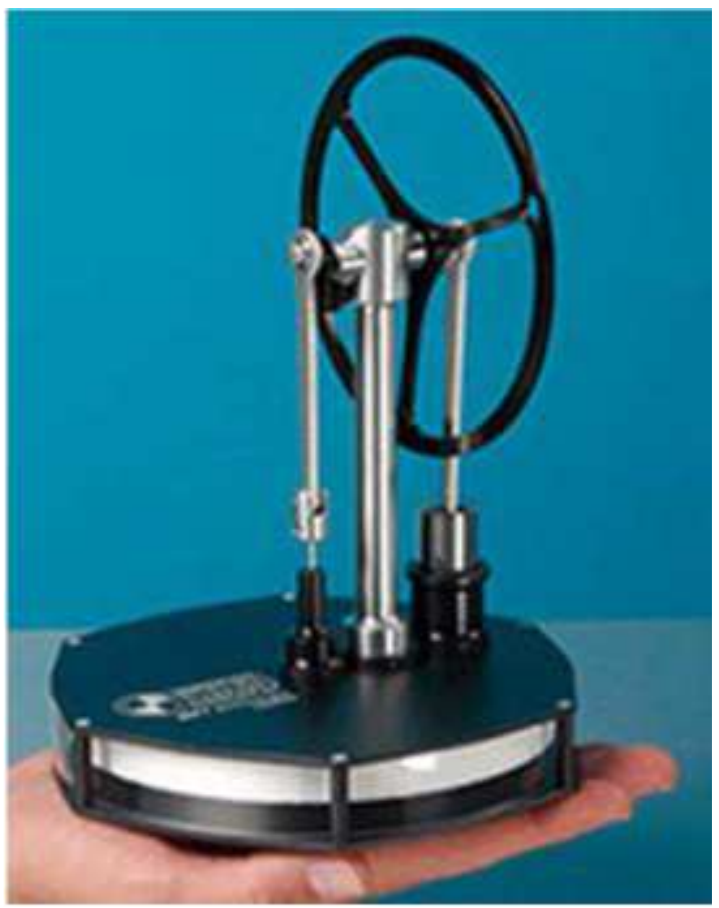

Fig. 14: Small experimental engines built to operate at low temperature differences of up to $7^{\circ} \mathrm{C}$ that occur, for example, between the palm of the hand and the environment

The regenerator was the key element invented by Robert Stirling and his presence or absence makes the distinction between the true Stirling engine and another hot aircar. On the basis of this, many engines that do not have a low-reserve visible regenerator can be categorized as Stirling engines in the sense that in the beta versions and the non-segmental discharge piston range, it and the cylinder surface make a regular heat exchange with the gas providing some recovery effect. This solution is often found in small models and LTD models where 
extra flow and unused volumes may be counterproductive and the lack of regenerator may be the optimal option (Petrescu and Petrescu, 2012a).

In a Stirling engine, the regenerator holds within the thermodynamic system a portion of the thermal energy at an intermediate temperature that would otherwise be changed to the environment, which will help bring the engine efficiency closer to that of the Carnot cycle by working between maximum and minimum temperatures.

The regenerator is a kind of heat exchanger in which the working fluid changes its flow direction periodically - not to be confused with a countercurrent heat exchanger in which two separate streams of fluid circulate in opposite directions on one side and the other Dividing Wall.

The purpose of the regenerator is to significantly increase efficiency by "recycling" the thermal energy in the cycle to reduce the heat fluxes in the two heat exchangers, often allowing the engine to provide more power with the same heat exchangers.

The regenerator is typically made up of an amount of metallic wires, preferably of low porosity to reduce unused space, with the axis placed perpendicular to the direction of the gas flow, forming a nipple filling. The regenerator is located in the gas circuit between the two heat exchangers. During the transfer of gas between the hot and the cold heat exchanger, $90 \%$ of its thermal energy is temporarily transferred to or recovered from the regenerator.

The regenerator mainly recycles unused heat, which reduces heat flows transmitted by the two heat exchangers (Petrescu and Petrescu, 2012a).

There is a need to give up some advantages in favor of others, especially in high-power (high-power and cylinder) motors (HTD engines), so the regenerator will need to be carefully designed to achieve high heat transfer at low losses due to hydrodynamic resistances and an unused space as small as possible. As with hot and cold heat exchangers, achieving a performance regenerator is an optimization problem between the three above-mentioned requirements.

The ideal Stirling cycle (Fig. 15) is a thermodynamic cycle with two isocorous and two isotherms. It is the most efficient thermodynamic cycle that is practically known to date, its theoretical efficiency equaling the hypothetical of a Carnot (ideal) cycle. However, the technical problems that appear to reduce the efficiency in its realization (the practical) - the construction of a simpler mechanism is more advantageous compared to the possibility of realizing a cycle as close as possible to the theoretical one (Petrescu and Petrescu, 2012a).

The working gas undergoes a series of successive dilations and compressions, consisting of two isothermal transformations and two isocratic transformations.

The ideal Carnot cycle for the Stirling engine

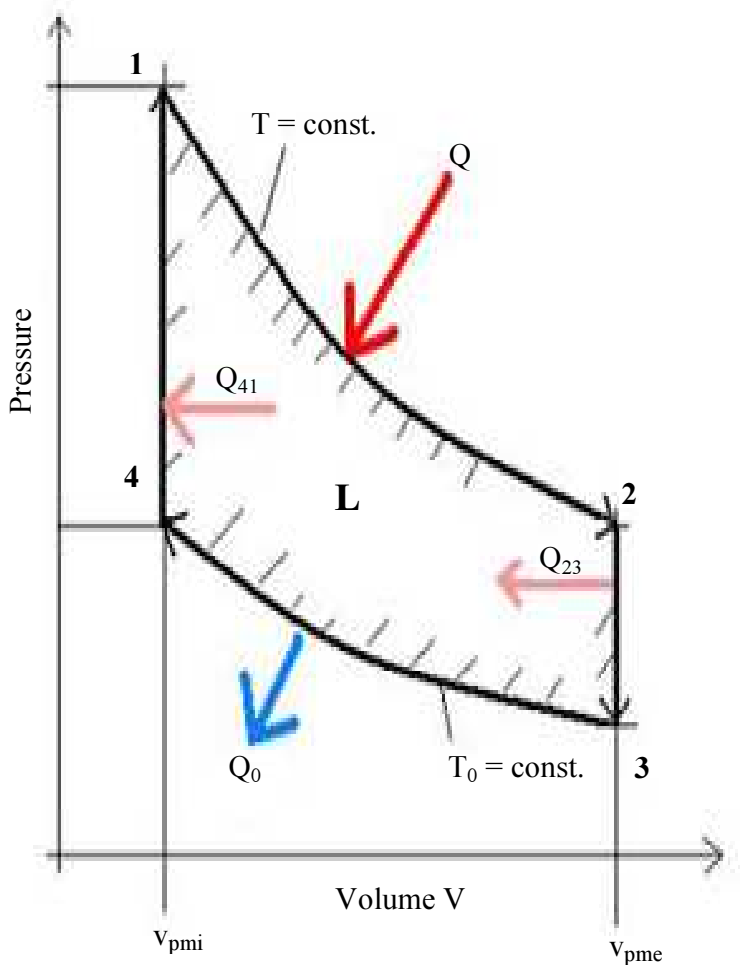

1-2 Isothermal dilatation

2-3 Cooling isolating

3-4 Isothermal compression

4-1 Heating isolating

Mechanical work done

$\mathrm{L}=\mathrm{Q}-\left|\mathrm{Q}_{0}\right|$

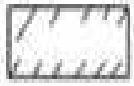

Internal heat exchange with discharged piston (Regenerator):

$\mathrm{Q}=|\mathrm{Q}|$

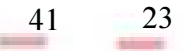

Fig. 15: The ideal stirling cycle 
Time 1: 1-2 on the graph is an isothermal (constant temperature) degradation during which the gas performs mechanical work on the environment. The heat absorbed $Q$ and the L12 mechanical work are linked by formula (I) (Petrescu and Petrescu, 2012a):

$$
Q_{12}=L_{12}=n \cdot R \cdot T \cdot \ln \frac{V_{2}}{V_{1}}
$$

Time 2: 2-3 on the graph is an isochoric cooling (at constant volume) during which the gas is brought to its initial state by heat transfer to the regenerator. The cured heat is determined by the formula (II):

$$
Q_{23}=n \cdot C_{v} \cdot\left(T-T_{0}\right)
$$

Time 3: 3-4 on the graph is an isothermal compression (it is constantly constant at constant temperature), where the mechanical work required to modify the volume L34 is equal to the cured heat, $Q_{0}$ (relation III):

$$
Q_{0} \equiv Q_{34}=L_{34}=n \cdot R \cdot T \cdot \ln \frac{V_{3}}{V_{4}}
$$

Time 4: 4-1 on the graph is an isocorous heating (takes place at constant volume) during which the heat absorbed by the regenerator during the regenerator is ceded to the gas (relation IV), its value being:

$$
Q_{41}=n \cdot C_{v} \cdot\left(T-T_{0}\right)
$$

The useful mechanical work appears in the $\mathrm{pV}$ diagram of Fig. 15, it being the area or area closed by the cycle curve, whereas in a Ts (entropy-temperature) diagram it would appear as a result of the difference between the absorbed and the calorific energy, being the one that produces the useful power $\mathrm{Wt}$, (relationship V):

$$
\left\{\begin{array}{l}
Q=Q_{0}+L \\
L=Q_{a b s}-Q_{c e d}=Q-Q_{0}
\end{array}\right.
$$

Using the formulas above for $Q$ and $Q_{0}$, the useful mechanical work takes the form of VI:

$$
\left\{\begin{array}{l}
L=n \cdot R \cdot T \cdot \ln \left(\frac{V_{2}}{V_{1}}\right)-n \cdot R \cdot T \cdot\left(\frac{V_{3}}{V_{4}}\right) \\
\Rightarrow L=n \cdot R \cdot\left(T \cdot \ln \left(\frac{V_{2}}{V_{1}}\right)-T_{0} \cdot \ln \left(\frac{V_{3}}{V_{4}}\right)\right) \\
\frac{V_{2}}{V_{1}}=\frac{V_{3}}{V_{4}}=\frac{V_{p m e}}{V_{p m i}} \Rightarrow \\
L=n \cdot R \cdot \ln \left(\frac{V_{p m e}}{V_{p m i}}\right) \cdot\left(T-T_{0}\right)
\end{array}\right.
$$

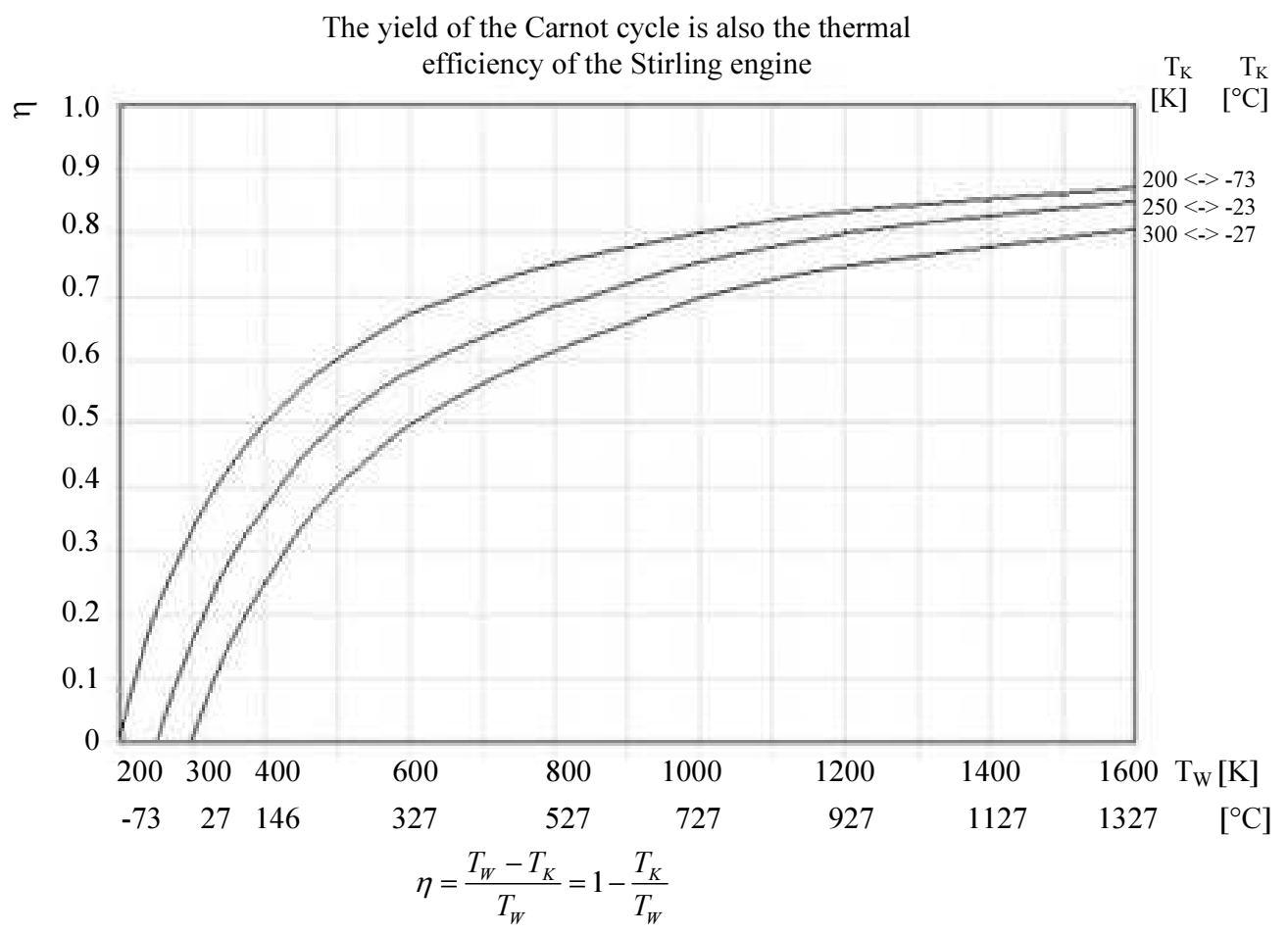

Fig. 16: The yield of the Carnot cycle is also the thermal efficiency of the Stirling engine 
The weakly stated point of the Stirling engines is the energy cycle yield (Carnot cycle yield). In principle, the Stirling engines can not achieve a high Carnot yield (Fig. 16), because the maximum working temperature is limited by the hot source temperature. In practice, the working gas cannot be heated above $800\left[{ }^{\circ} \mathrm{K}\right]\left(527\left[{ }^{\circ} \mathrm{C}\right]\right)$. At these low temperature differences the Carnot yield is about $66 \%$ and is thus much lower than that of the internal combustion engines. Internal combustion engines frequently reach temperatures of $727\left[{ }^{\circ} \mathrm{C}\right]\left(1000\left[{ }^{\circ} \mathrm{K}\right]\right)$, for which Carnot's energy efficiency is about $76 \%$.

This problem also occurs in thermal power stations equipped with steam generating turbines that reach $66 \%$ of their Carnot yield, resulting in an effective efficiency of just over $40 \%$. The current Stirling engines reach 50 $60 \%$ of their Carnot yield and work with a correspondingly lower effective efficiency.

We aim to bring some improvements to the Stirling engine from a mechanical point of view, improvements that will also affect its thermal performance, so these improvements can create a new Stirling engine that works with a superior mechanical efficiency (Petrescu and Petrescu, 2012a).

Improvements of the proposed mechanical nature will be presented in the Results section.

\section{Results}

\section{Determination of Mechanical Efficiency in Piston- Rod-Crank System}

The piston crank shaft has many uses, being used mainly in two main ways, as a motor or compressor. In four-stroke internal combustion engines, the piston crank shaft mechanism is a single-stroke engine of the total of four (Grunwald, 1980). In the other three times, the mechanism behaves like a compressor, receiving the power (being driven) from the crank (crankshaft) and pushing the piston (in the two compression or discharge times) or pulling it (at the intake). Practically, the fourstroke engine power cycle is completed in two complete kinematic cycles (Petrescu and Petrescu, 2012a).

The efficiency of the motor mechanism (driven by piston power) differs from that of the compressor mechanism (driven by the crankcase) (Grunwald, 1980; Hargreaves, 1991; Homețescu, 2003; Martini, 1978; Petrescu and Petrescu, 2014a; 2014b; 2014c; 2012a; 2005a; 2005b; 2003; Petrescu, 2012).

For this reason, the two distinct cases will be studied separately:

A. When the mechanism works in the engine mode, being driven by the piston

B. When the mechanism works in the compressor (or pump) mode, it is driven by the crankshaft
Figure 17 shows the kinematic diagram of the piston crank shaft mechanism. The constructive parameters of the mechanism are: $r$, the crank radius (or the distance from the spindle spindle axis to the spindle spindle axis); $l$, spike length (distance from spindle spindle axis to spindle pin spindle); e, the eccentricity (distance from the spindle spindle axis to the piston guide axis). The mechanism is positioned by the angle, $j$, which represents the angle of rotation and positioning of the crank. White is positioned at one of the two angles, a or $y$ (Fig. 17). The distance from the center of rotation of the crank $\mathrm{O}$ to the center of the piston bolt $\mathrm{B}$, projected on the translation axis of the piston, is marked with the variable $y_{B}$ (Petrescu and Petrescu, 2012a).

We design the vector equation of the contour of the mechanism on two rectangular planar axes Ox and Oy and obtain the two scalar positions of the mechanism given by the position system 1 (Fig. 17):

$\left\{\begin{array}{l}r \cdot \cos \varphi+l \cdot \cos \psi=-e \\ r \cdot \sin \varphi+l \cdot \sin \psi=y_{B}\end{array}\right.$

It is customary to solve the disconnected position system (1), from the first relation of the system to the $y$-axis cosine (according to relation 2) and the second one to isolate the displacement $s$ of the piston (according to relation 3 ):

$\cos \psi=-\frac{e+r \cdot \cos \varphi}{l}$

$s=y_{B}=r \cdot \sin \varphi+l \cdot \sin \psi$

By deriving the position system (1), the speed system (4) is obtained:

$\left\{\begin{array}{l}-r \cdot \dot{\varphi} \cdot \sin \varphi-l \cdot \dot{\psi} \cdot \sin \psi=0 \\ r \cdot \dot{\varphi} \cdot \cos \varphi+l \cdot \dot{\psi} \cdot \cos \psi=\dot{y}_{B}\end{array}\right.$

From the first relation of the system (4) the angular velocity (according to relation 5) is calculated and the linear velocity of the piston (relation 6) is determined from the second velocity (4) equation:

$\dot{\psi}=-\frac{r \cdot \sin \varphi}{l \cdot \sin \psi} \cdot \dot{\varphi}$

$\dot{y}_{B}=r \cdot \dot{\varphi} \cdot \cos \varphi+l \cdot \dot{\psi} \cdot \cos \psi$

The velocity system (4) is also derived in order to obtain the acceleration system (7):

$\left\{\begin{array}{l}-r \cdot \dot{\varphi}^{2} \cdot \cos \varphi-l \cdot \dot{\psi}^{2} \cdot \cos \psi-l \cdot \ddot{\psi} \cdot \sin \psi=0 \\ -r \cdot \dot{\varphi}^{2} \cdot \sin \varphi-l \cdot \dot{\psi}^{2} \cdot \sin \psi-l \cdot \ddot{\psi} \cdot \cos \psi=\ddot{y}_{B}\end{array}\right.$ 


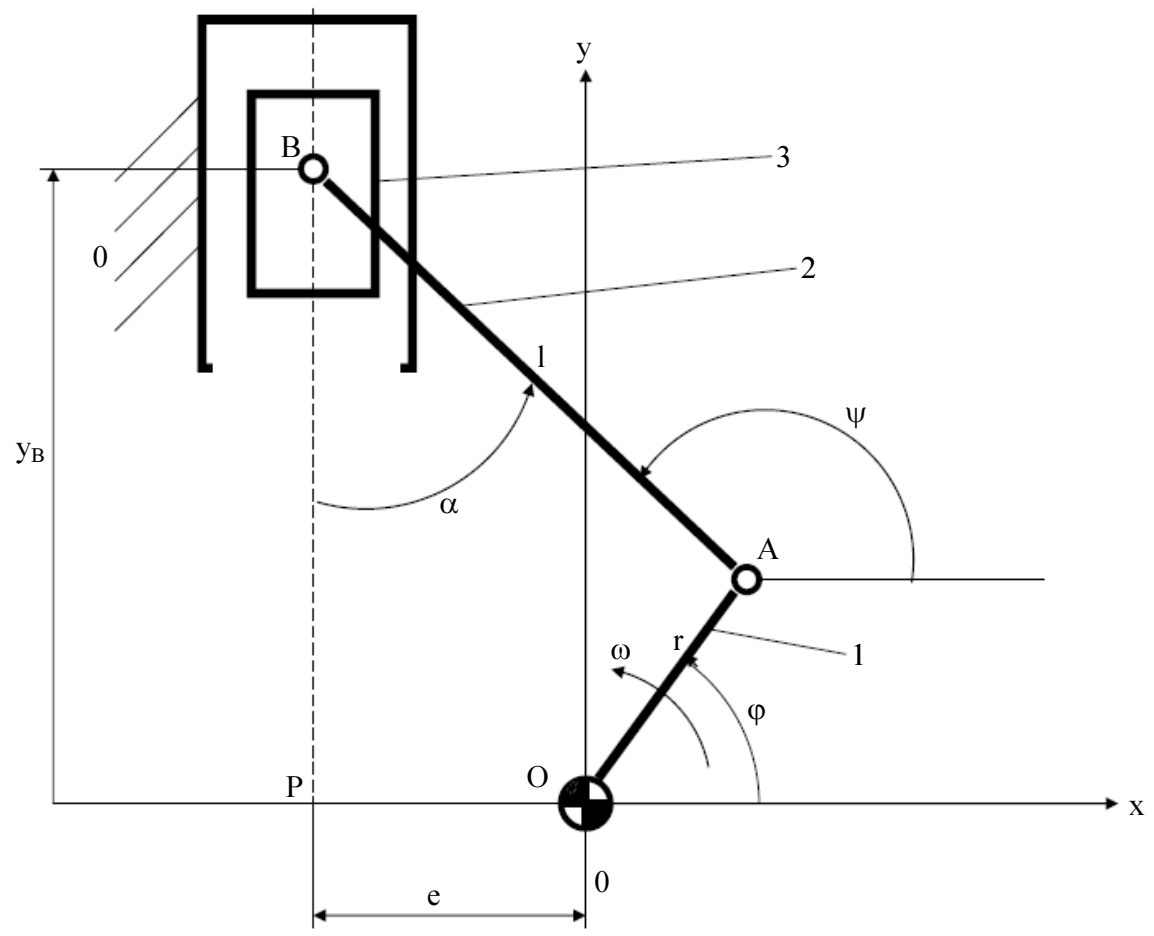

Fig. 17: The kinematic scheme of the piston crankshaft mechanism

From the first equation of the system (7) the angular acceleration $\ddot{\psi}$ (according to relation 8) is calculated and from the second equation of the system (7) the linear acceleration of the piston $\ddot{y}_{B}$, (relation 9) is determined:

$\ddot{\psi}=-\frac{r \cdot \dot{\varphi}^{2} \cdot \cos \varphi+l \cdot \dot{\psi}^{2} \cdot \cos \psi}{l \cdot \sin \psi}$

$\ddot{y}_{B}=l \cdot \ddot{\psi} \cdot \cos \psi-r \cdot \dot{\varphi}^{2} \cdot \sin \varphi-l \cdot \dot{\psi}^{2} \cdot \sin \psi$

Angle $\alpha$ is expressed according to the angle $\psi$, according to the expression (10):

$\alpha=\psi-90$

The links between the basic trigonometric functions of these angles are expressed by system relations (11):

$\left\{\begin{array}{l}\cos \alpha=\sin \psi \\ \sin \alpha=-\cos \psi\end{array}\right.$

The sinus of the angle $\alpha, \sin \alpha$ is expressed by the relationship (2) and the second equality in the system (11), obtaining the relation of the form (12):

$\sin \alpha=\frac{e+r \cdot \cos \varphi}{l}$
The speed of the piston takes shape (13) (Petrescu and Petrescu, 2012a):

$\left\{\begin{array}{l}v_{B}=\dot{y}_{B}=r \cdot \dot{\varphi} \cdot \cos \varphi+l \cdot \dot{\psi} \cdot \cos \psi \\ =r \cdot \dot{\varphi} \cdot \cos \varphi-\frac{r \cdot \dot{\varphi} \cdot \sin \varphi \cdot \cos \psi}{\sin \psi} \\ =\frac{r \cdot \dot{\varphi}}{\sin \psi} \cdot(\cos \varphi \cdot \sin \psi-\sin \varphi \cdot \cos \psi) \\ =r \cdot \dot{\varphi} \cdot \frac{\sin (\psi-\varphi)}{\sin \psi}=r \cdot \omega \cdot \frac{\sin (\psi-\varphi)}{\sin \psi} \\ v_{B}=r \cdot \omega \cdot \frac{\sin (\psi-\varphi)}{\sin \psi}\end{array}\right.$

The piston crank shaft mechanism works in the engine mode for a single time in the four (or two) times of the power cycle of the four-stroke Otto or Diesel engine (or two-stroke engines respectively type Stirling).

The engine time has a corresponding crank movement of about 180 degrees (about $\mathrm{p}$ radians) when the piston moves from the dead point to the distant dead point (i.e., when the piston moves between its two extreme positions, but necessarily from the minimum volume to the maximum working volume of the respective cylinder - Fig. 18), the crank from position a (in extension to white) and reaching position $b$ (overlaid over white); this is the driving time of the energy cycle. 


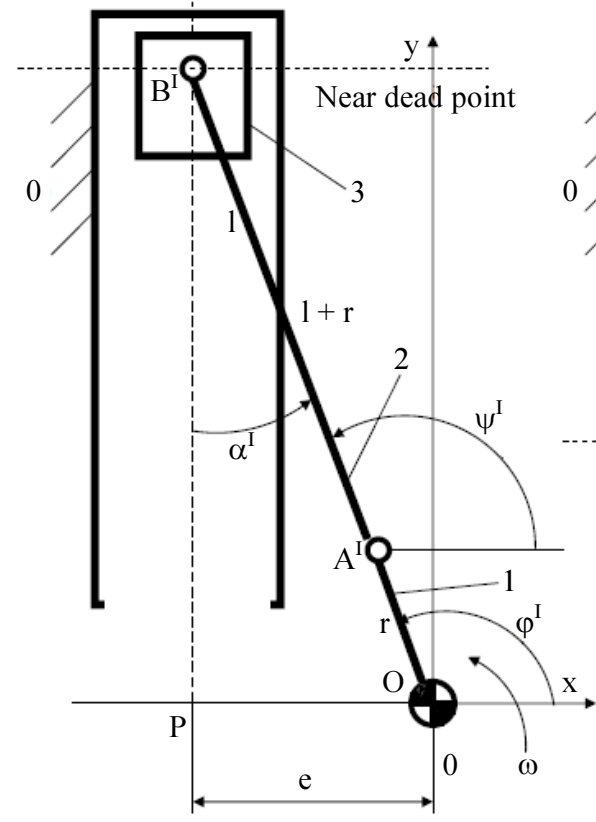

The crank is in prolonging with the connecting-rod

(a)

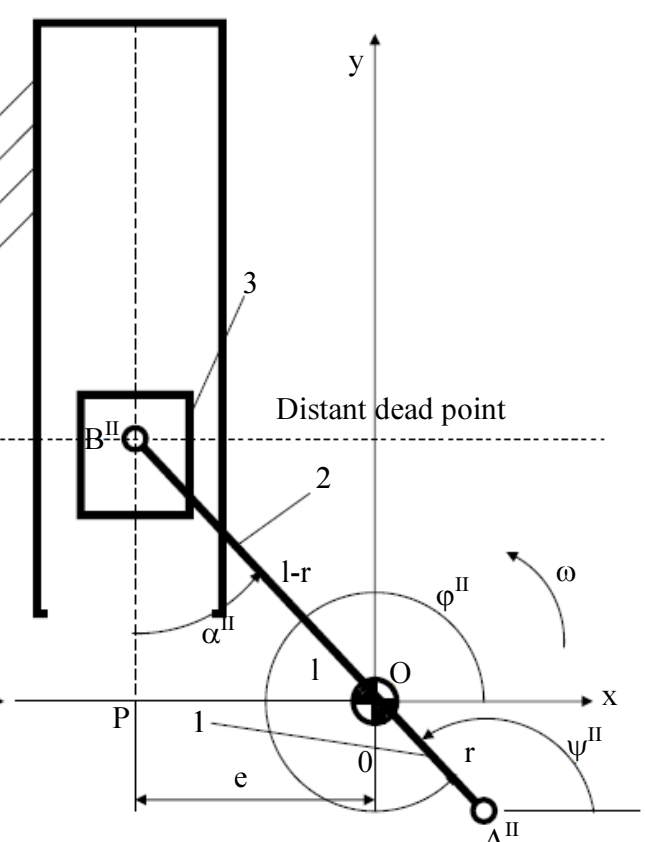

The crank is overlapped on the connecting-rod

(b)

Fig. 18: Kinematic schemes of the engine mechanism in extreme positions (a) When the crank is in the extension of the bar (b) When the crank overlaps over the bar

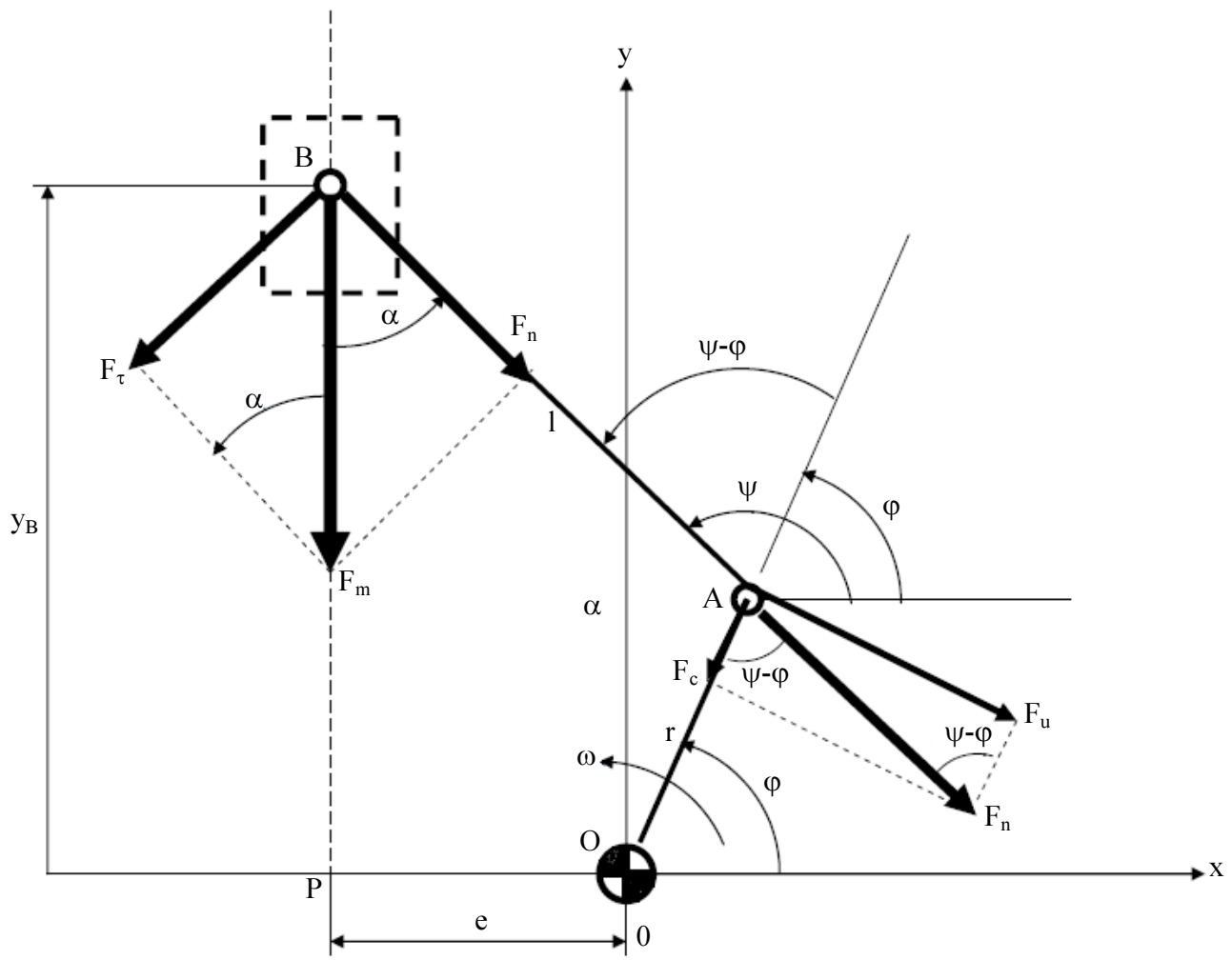

Fig. 19: The forces in the piston crank mechanism, when the power (the driving force) is transmitted from the piston to the crank 
For Otto or Diesel engines, the energy cycle contains two kinematic cycles (the big disadvantage of these engines), while the Lenoir, Stirling, Wankel, Atkinson engines overlap with the kinematic (the big advantage of these engines).

To determine the efficiency of the piston crank shaft mechanism when working as a motor, it is necessary to determine the force distribution in the mechanism going from the piston to the crank (Fig. 19).

The engine power, consumed (input force) $F_{m}$, is divided into two components: (1) $F_{n}$ - normal force (oriented along the rod); (2) $\mathrm{F}_{\tau}$ - tangential force (perpendicular to B, per bar); see system (14); (Fig. $18 \omega$ is negative, the crank being printed with an hourly rotation):

$\left\{\begin{array}{l}F_{n}=F_{m} \cdot \cos \alpha=F_{m} \cdot \sin \psi \\ F_{\tau}=F_{m} \cdot \sin \alpha=-F_{m} \cdot \cos \psi\end{array}\right.$

Fn is the only force transmitted through the bead (along it) from B to A (because the bar has its characteristic, general, rotary, roto-translational movement, having no direct link to the bead; when the bar has a connection, a coupling to the fixed element, it turns from the bar to the rocker and it can only transmit moment, the third possible case is that of a bar that slides in a cylinder that also has a rotation lock with the bar, there is a multiple rotation and translation coupling, in which case the bar will have a movement of the rod passing through it along a force, but there will also be a rotation movement around the coupling with the beam thus transmitting momentum.

In $\mathrm{A}$, the force $F_{n}$ is also divided into two components: 1. $F_{u}$ - the force that is perpendicular to the crank; and 2. $F_{c}$ - compressive or tensile force acting along the crank. See system (15):

$\left\{\begin{array}{l}F_{u}=F_{n} \cdot \sin (\psi-\varphi)=F_{m} \cdot \sin \psi \cdot \sin (\psi-\varphi) \\ F_{c}=F_{n} \cdot \cos (\psi-\varphi)=F_{m} \cdot \sin \psi \cdot \cos (\psi-\varphi)\end{array}\right.$

The useful power $P_{u}$ can be written as (16):

$P_{u}=F_{u} \cdot v_{A}=F_{u} \cdot r \cdot \omega$

$=F_{m} \cdot r \cdot \omega \cdot \sin \psi \cdot \sin (\psi-\varphi)$

The power consumed by $P_{c}$ takes the form of the expression (17):

$P_{c}=F_{m} \cdot v_{B}=F_{m} \cdot r \cdot \omega \cdot \frac{\sin (\psi-\varphi)}{\sin \psi}$

The instantaneous $\eta_{i}$ mechanical yield can be expressed using the relation (18):

$$
\left\{\begin{array}{l}
\eta_{i}=\frac{P_{u}}{P_{c}}=\frac{F_{m} \cdot r \cdot \omega \cdot \sin \psi \cdot \sin (\psi-\varphi)}{F_{m} \cdot r \cdot \omega \cdot \sin (\psi-\varphi) \cdot \frac{1}{\sin \psi}} \\
=\sin ^{2} \psi=\cos ^{2} \alpha=1-\frac{(e+r \cdot \cos \varphi)^{2}}{l^{2}}
\end{array}\right.
$$

In order to calculate the mechanical efficiency $\eta$, the expression of the instantaneous efficiency $\eta_{i}$ from the near dead point to the distant dead point, from $\varphi^{\mathrm{I}}$ to $\varphi^{\mathrm{II}}$ (Fig. 19, system 19) can be integrated:

$\left\{\begin{array}{l}\varphi^{I} \equiv \varphi_{i}=\pi-a \cos \left(\frac{e}{l+r}\right) \\ \varphi^{I I} \equiv \varphi_{f}=2 \cdot \pi-a \cos \left(\frac{e}{l-r}\right)\end{array}\right.$

It is possible to determine more easily the mechanical efficiency starting from the system (18) but not using the variable $\varphi$ with the limits given by (19), but the variable $\alpha$, when the extreme values of the angle $\alpha, \alpha_{M}$ and $\alpha_{m}$ are known (or can be determined) (relations 20-22).

The misalignment e reduces yield, so it will take $e=0$.

A ratio $r / l=\lambda$ can be adopted so small that a convenient yield is achieved at the engine mechanism. As typically $\lambda$ is constructively chosen less than 0.3 , the mechanical efficiency of the engine mechanism (the piston crank engine during engine) is more than $96 \%$, provided that the deaeration is zero. The piston crank shaft mechanism, when working in the engine, has a very good mechanical (very high) efficiency:

$$
\left\{\begin{array}{l}
\eta=\frac{1}{\Delta \alpha} \cdot \int_{\alpha_{m}}^{\alpha_{M}} \eta_{i} \cdot d \alpha=\frac{1}{\Delta \alpha} \int_{\alpha_{m}}^{\alpha_{M}} \cos ^{2} \alpha \cdot d \alpha \\
=\frac{1}{\Delta \alpha} \int_{\alpha_{m}}^{\alpha_{M}} \frac{\cos (2 \cdot \alpha)+1}{2} \cdot d \alpha \\
=\frac{1}{2 \cdot \Delta \alpha} \int_{\alpha_{m}}^{\alpha_{M}}(\cos (2 \alpha)+1) \cdot d \alpha \\
=\frac{1}{2 \cdot \Delta \alpha} \cdot\left[\frac{1}{2} \cdot \sin (2 \cdot \alpha)+\alpha\right]_{\alpha_{m}}^{\alpha_{M}} \\
=\frac{1}{2 \cdot \Delta \alpha}\left[\frac{\sin \left(2 \alpha_{M}\right)-\sin \left(2 \alpha_{m}\right)}{2}+\Delta \alpha\right. \\
=\frac{\sin \left(2 \cdot \alpha_{M}\right)-\sin \left(2 \cdot \alpha_{m}\right)}{4 \cdot \Delta \alpha}+0.5 \\
=\frac{\sin \left(2 \cdot \alpha_{M}\right)-\sin \left(2 \cdot \alpha_{m}\right)}{4 \cdot\left(\alpha_{M}-\alpha_{m}\right)}+0.5 \\
=0.5+\frac{\sin \alpha_{M} \cos \alpha_{M}-\sin \alpha_{m} \cos \alpha_{m}}{2 \cdot\left(\alpha_{M}-\alpha_{m}\right)}
\end{array}\right.
$$




$$
\begin{aligned}
& \left\{\begin{array}{l}
\text { For } l>r+e \Rightarrow \alpha_{M}=\arcsin \left(\frac{r+e}{l}\right) \\
\text { For } r>e \Rightarrow \alpha_{m}=0
\end{array}\right. \\
& \left\{\begin{array}{l}
\text { For } \lambda \leq 0,1(6) \Rightarrow \eta \geq 0,99 \equiv 99 \% \\
\text { For } \lambda=0,(3) \Rightarrow=0,962 \equiv 96,2 \% ; \\
\text { For } \lambda=0,5 \Rightarrow \eta=0,913 \equiv 91,3 \%
\end{array}\right.
\end{aligned}
$$

The piston crank shaft mechanism (system) works as a motor mechanism (with piston actuation), as we have shown in one time, a single stroke within an energy cycle, the other one or three times being working times in the regimen crank (with crank drive - from crankshaft).

On two-stroke cylinders (cylinders), one of the times is the engine and at the other time the engine is driven from the crank. Four-stroke engine cylinders except for the Stirling have one engine time out of the four, all three other with crank drive, which greatly reduces the efficiency of these engines because the mechanical efficiency of crank drive is about two times lower than that of an actual engine time, as will be seen immediately.

In this respect, the four-stroke four-stroke engine type Stirling is the most advantageous, being driven continuously from the piston (thus always having a maximum drive motor drive).

For this reason, it has a stranger load feature, which is said to be inappropriate for car use (the more crankshaft driven crankshaft, although having less mechanical efficiency, have a much longer stable and respond quickly to changes in the working regimes required by a vehicle, especially due to the large inertial help of the shaft, plus the steering wheel, which are more "nerve-wise" and therefore more dynamic).

This can, however, be easily corrected in Stirling engines by using multiple cylinders simultaneously, trapped on the same shaft (multi-cylinder Stirling), the shaft having a high inertia, which can be further enhanced by -a wheel.

Even though the cylinders work most of the time in motor regimes, they are permanently connected to the output shaft which must have a very high inertia in construction, the movement at the output of the motor being picked from the shaft.

Further, the piston rod crank system, if it is driven from the crank (from the crankshaft, Fig. 20), will be studied.

We determine the distribution of forces and on the basis of them and the known speeds we will already be able to calculate the powers and the mechanical efficiency of the system.

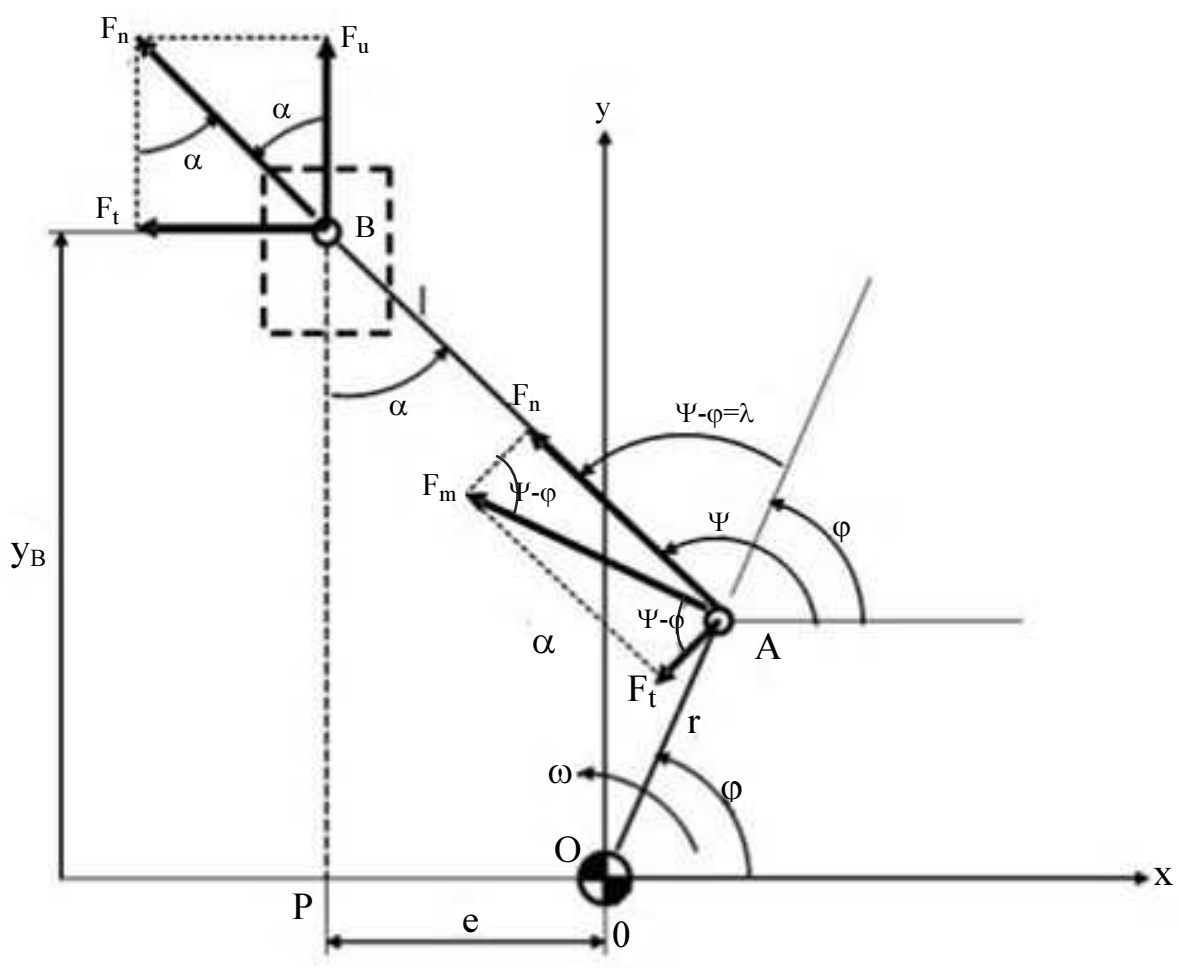

Fig. 20: The forces in a piston crankshaft, when it is driven from the crank 
The input force, the driving force (consumed motor force), Fm, perpendicular to A on the crank OA (r), is divided into two components: $1 . F_{n}$ - the normal force representing the active component, the only component transmitted from the coupling A to Coupling B through the bead (where forces are transmitted only along it); 2 . $F_{\tau}$ - tangential force, which, although not transmitted by the bead, can rotate and deform it elastically at the same time (bending); the equations to determine the two components are given by the system (23):

$$
\left\{\begin{array}{l}
F_{n}=F_{m} \cdot \sin (\psi-\varphi) \\
F_{\tau}=F_{m} \cdot \cos (\psi-\varphi)
\end{array}\right.
$$

In Coupling B, the transmitted $F_{n}$ force is divided into two components: 1. $F_{u}$ - force; $2 . F_{r}$ - a normal force on the guide axis (the axis of the guide); see the equation system (24):

$\left\{\begin{array}{l}F_{u}=F_{n} \cdot \cos \alpha=F_{n} \cdot \sin \psi=F_{m} \cdot \sin (\psi-\varphi) \cdot \sin \psi \\ F_{r}=F_{n} \cdot \sin \alpha=-F_{n} \cdot \cos \psi=-F_{m} \cdot \sin (\psi-\varphi) \cdot \cos \psi\end{array}\right.$

The useful power can be written in the form (25) and the one consumed takes shape (26):

$$
\begin{aligned}
& P_{u}=F_{u} \cdot v_{B}=F_{m} \cdot \sin (\psi-\varphi) \cdot \sin \psi \cdot \frac{r \omega \sin (\psi-\varphi)}{\sin \psi} \\
& =F_{m} \cdot r \cdot \omega \cdot \sin ^{2}(\psi-\varphi) \\
& P_{c}=F_{m} \cdot v_{A}=F_{m} \cdot r \cdot \omega
\end{aligned}
$$

The instantaneous mechanical efficiency of the crank-shaft crankshaft driven by the crank can be determined by the relationship (27):

$$
\begin{aligned}
& \eta_{i}=\frac{P_{u}}{P_{c}}=\frac{F_{m} \cdot r \cdot \omega \cdot \sin ^{2}(\psi-\varphi)}{F_{m} \cdot r \cdot \omega}=\sin ^{2}(\psi-\varphi) \\
& =\frac{\left[\sqrt{l^{2}-(e+r \cdot \cos \varphi)^{2}} \cdot \cos \varphi+(e+r \cdot \cos \varphi) \cdot \sin \varphi\right]^{2}}{l^{2}}
\end{aligned}
$$

In order to determine the mechanical efficiency of the crankshaft system, it would be difficult to integrate the middle expression of the system (27) when the integration variable is the angle $\varphi$ (integration being possible only by approximate methods, which would not allow for a final expression).

Using the angles $\psi$ and $\varphi$ as the variable, the integrated relationship (the first part of the system 27) is simplified. But it is even easier to integrate the relation (27) from the bottom when we have a single variable, $\lambda$ (relation 28):

$$
\left\{\begin{array}{l}
\eta=\frac{1}{\Delta \lambda} \cdot \int_{\lambda_{m}}^{\lambda_{M}} \eta_{i} \cdot d \lambda=\frac{1}{\Delta \lambda} \int_{\lambda_{m}}^{\lambda_{M}} \sin ^{2} \lambda \cdot d \lambda \\
=\frac{1}{\Delta \lambda} \int_{\lambda_{m}}^{\lambda_{M}} \frac{1-\cos (2 \cdot \lambda)}{2} \cdot d \lambda=\frac{1}{2 \cdot \Delta \lambda} \int_{\lambda_{m}}^{\lambda_{M}}(1-\cos (2 \cdot \lambda)) \cdot d \lambda \\
=\frac{1}{2 \cdot \Delta \lambda} \cdot\left[\lambda-\frac{1}{2} \cdot \sin (2 \cdot \lambda)\right]_{\lambda_{m}}^{\lambda_{M}} \\
=\frac{1}{2 \cdot \Delta \lambda}\left[\Delta \lambda-\frac{\sin \left(2 \lambda_{M}\right)-\sin \left(2 \lambda_{m}\right)}{2}\right] \\
=\frac{1}{2}-\frac{\sin \left(2 \cdot \lambda_{M}\right)-\sin \left(2 \cdot \lambda_{m}\right)}{4 \cdot \Delta \lambda} \\
=0,5-\frac{\sin \left(2 \cdot \lambda_{M}\right)-\sin \left(2 \cdot \lambda_{m}\right)}{4 \cdot\left(\lambda_{M}-\lambda_{m}\right)} \\
=0,5-\frac{\sin \lambda_{M} \cdot \cos \lambda_{M}-\sin \lambda_{m} \cdot \cos \lambda_{m}}{2 \cdot\left(\lambda_{M}-\lambda_{m}\right)}
\end{array}\right.
$$

As it results from the final relations (28), the mechanical efficiency of the crankcase crankshaft driven by the crankshaft (motor shaft) cannot exceed the maximum value of $50 \%$.

So, at optimal design, the efficiency of the crank shaft crankshaft piston system is approaching 100\% and that of the crankshaft (the motor shaft) is below $50 \%$, it follows that the best cylinder system is the one that is permanently driven from the piston, i.e. the Stirling engine.

In a stirring engine, the mechanical efficiency over the entire energy cycle (which coincides with the kinematic cycle) is about $80-99.9 \%$ depending on the design mode. The thermal yield (of the Carnot cycle) for optimal high temperature operation (as seen in the first chapter) reaches $55-65 \%$.

It results that the total (final) yield of a well-designed Stirling, with a hot source of high temperatures, reaches between $44 \%$ and $65 \%$, which means a lot. No other thermal engine reaches such values.

Because some say that Stirling has lower returns than Otto or Diesel and others, on the contrary, that Stirling's performance is its strong point, we need to make a more detailed discussion at this point. What benefit does Otto and Diesel achieve at a heat output of $65-75 \%$ compared to only $55-65 \%$ in the Stirling engines, if the final output of an engine is the product of its thermal and mechanical efficiency and in terms of mechanical efficiency a Stirling in a four-stroke, welldesigned, can achieve theoretically $99.999 \%$ (i.e., almost $100 \%$ ), while a four-stroke Diesel or Otto will practically achieve a mechanical efficiency of no more than $56 \%(3 * 45 \%+90 \%): 4]$ so that the total (final) output of an Otto or Diesel will be only about $39 \%$ $\left(56^{*} 70\right)$, well below the maximum of a Stirling, $65 \%$. 
Let's recall that for a long time the Otto or Diesel engines were running at a final yield of only $12-20 \%$ and with a high weight they reached the final yields of $25-30 \%$, while the Stirling engines reached 50-65\%?

However, engines in $\mathrm{V}$ are able to achieve higher overall yields. With a mechanical efficiency of about $70 \%$ and a maximum thermal level of $75 \%$, an Otto or Diesel engine in $\mathrm{V}$ can achieve a final yield of about $52-53 \%$.

Constructively, a piston cylinder version with the piston stroke as small as possible and the largest bore should be adopted.

\section{Dynamic Kinematic of the Rod Piston Crank System}

The cinematic of the piston crankshaft mechanism of Fig. 21 is generally known to be solved by the relationships (A1-A13):

$$
\begin{aligned}
& \{r \cdot \cos \varphi+l \cdot \cos \psi=-e \\
& \left\{r \cdot \sin \varphi+l \cdot \sin \psi=y_{B}\right. \\
& \cos \psi=-\frac{e+r \cdot \cos \varphi}{l} \\
& s=y_{B}=r \cdot \sin \varphi+l \sin \psi \\
& \left\{\begin{array}{l}
-r \cdot \dot{\varphi} \cdot \sin \varphi-l \cdot \dot{\psi} \cdot \sin \psi=0 \\
r \cdot \dot{\varphi} \cdot \cos \varphi+l \cdot \dot{\psi} \cdot \cos \psi=\dot{y}_{B}
\end{array}\right. \\
& \dot{\psi}=-\frac{r \cdot \sin \varphi}{l \cdot \sin \psi} \cdot \dot{\varphi}
\end{aligned}
$$

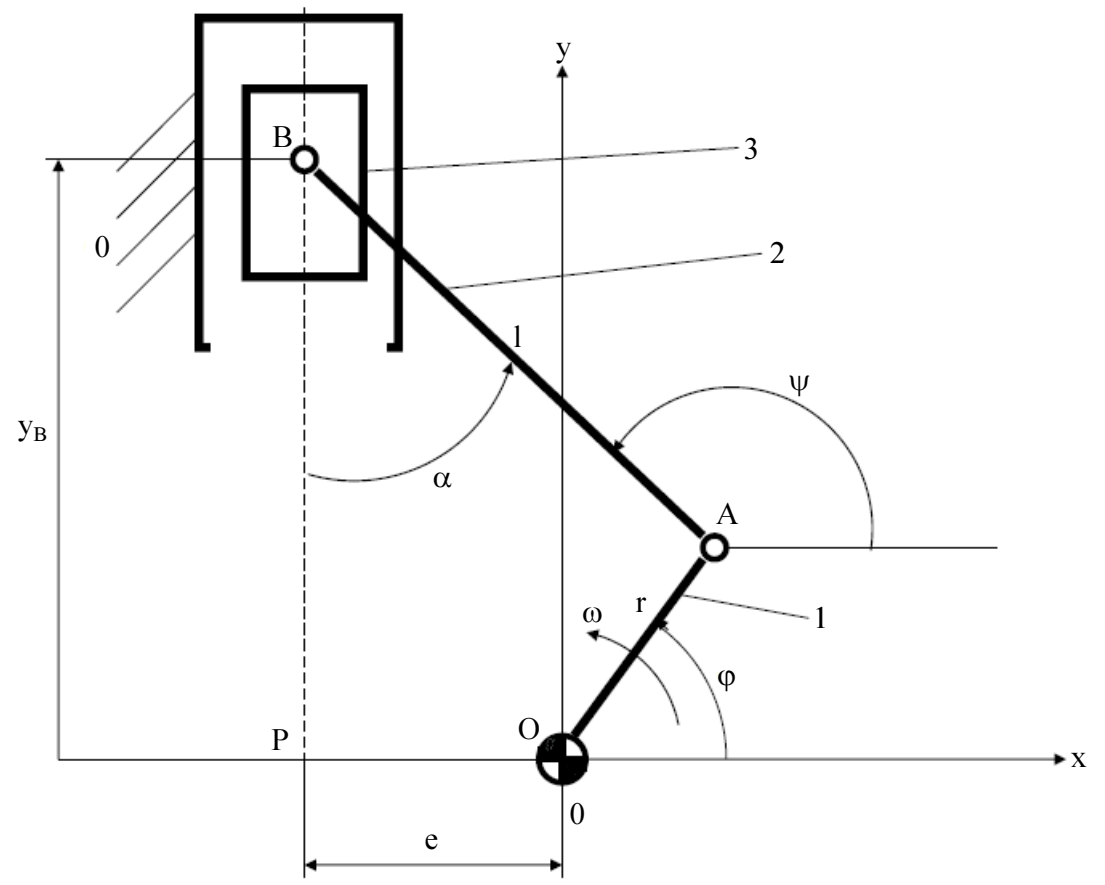

Fig. 21: The kinematic scheme of the piston crankshaft mechanism 


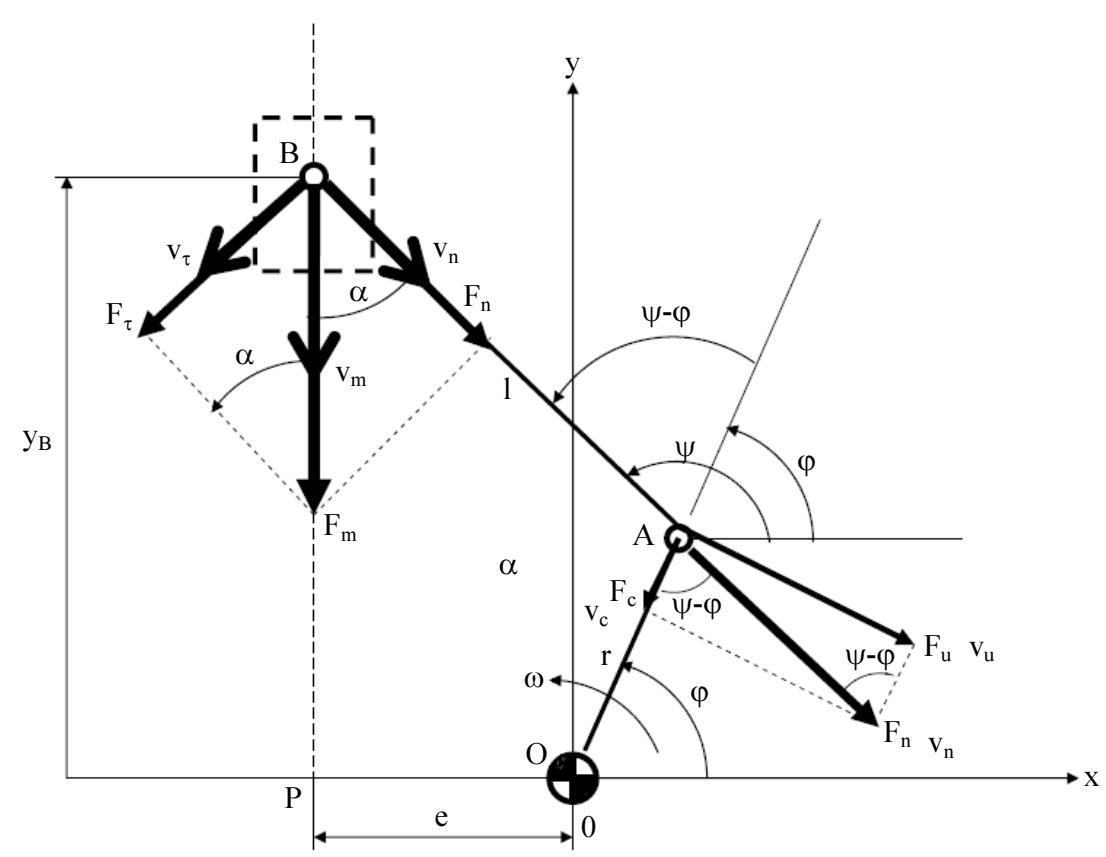

Fig. 22: Dynamic forces and speeds in the piston crank shaft mechanism, when power is transmitted from the piston to the crank

In Dynamic Cinematic, the (dynamic) velocities are aligned in the direction of the forces as is natural, so that they no longer coincide with the kinematic speeds imposed by the couplings of the mechanism (Fig. 22). Dynamic speeds due to forces occur, speeds that represent the dynamic kinematics (the influence of inertial forces, influence that determines the final dynamic aspect of speeds).

The dynamic kinematics is therefore the kinematic study of the displacements, speeds and accelerations resulting from the direction of operation of the velocities following the direction of the forces. The expressions of velocity in the dynamic kinematics are easily obtained, it is derived in relation to the time to determine the expressions of the accelerations in the dynamic kinematics and the expressions of the velocities are integrated in order to obtain the corresponding movements. Determining the movements in the dynamic cinematic becomes therefore more difficult.

To begin with, we will determine the velocities in the dynamic kinematics for piston crank shaft mechanism actuated by the piston (Fig. 22). We can write the relationships (A14-A16):

$$
\begin{aligned}
& v_{B}=v_{m} \\
& v_{n}=v_{m} \cdot \cos \alpha=v_{m} \cdot \sin \psi \\
& v_{u}=v_{n} \cdot \sin (\psi-\varphi)=v_{m} \cdot \sin \psi \cdot \sin (\psi-\varphi)
\end{aligned}
$$

We also want to find out the dynamic performance, more precisely the mechanical efficiency instantly when the mechanism has dynamic regimes and the speeds are those in the dynamic cinematic, the actuation of the mechanism being of the motor type, i.e., from the piston.

The useful force is determined by the relation (A17) presented in the previous chapter:

$F_{u}=F_{n} \cdot \sin (\psi-\varphi)=F_{m} \cdot \sin \psi \cdot \sin (\psi-\varphi)$

The useful power is written in this case in form A18:

$\left\{\begin{array}{l}P_{u}=F_{u} \cdot v_{u} \\ =F_{m} \cdot \sin \psi \cdot \sin (\psi-\varphi) \cdot v_{m} \cdot \sin \psi \cdot \sin (\psi-\varphi) \\ =F_{m} \cdot v_{m} \cdot \sin ^{2} \psi \cdot \sin ^{2}(\psi-\varphi)\end{array}\right.$

Expression of power consumed is given by relationship A19:

$P_{c}=F_{m} \cdot v_{m}$

We can now determine the dynamic yield, more precisely the dynamic dynamic dynamics (relationship A20):

$\eta_{i}^{D M}=\frac{P_{u}}{P_{c}}=\sin ^{2} \psi \cdot \sin ^{2}(\psi-\varphi)=\eta_{i} \cdot D^{M}$

where, $\eta_{i}$ is the instantaneous mechanical efficiency of the crank shaft piston actuated by the piston and $D^{M}$ is a dynamic coefficient, which for the piston-driven piston crank mechanism (in Motor mode) has the expression A21: 


$$
D^{M}=\sin ^{2}(\psi-\varphi)=\sin ^{2}(\varphi-\psi)
$$

In this case, let us recall that the instantaneous mechanical efficiency has the expression A22:

$\eta_{i}=\sin ^{2} \psi$

It should be noted that the dynamic yield is precisely the product of the known, simple (cinematic) yield and the dynamic coefficient (relation A23):

$$
\eta_{i}^{D M}=\eta_{i} \cdot D^{M}
$$

The kinematic expression of the speed of point B (relationship A24) is known:

$$
v_{m} \equiv v_{B}=v_{A} \cdot \frac{\sin (\psi-\varphi)}{\sin \psi}
$$

With relation A24 introduced in formula A16, velocity vu takes shape A25:

$$
\left\{\begin{array}{l}
v_{u}=v_{n} \cdot \sin (\psi-\varphi)=v_{m} \cdot \sin \psi \cdot \sin (\psi-\varphi) \\
=v_{A} \cdot \frac{\sin (\psi-\varphi)}{\sin \psi} \cdot \sin \psi \cdot \sin (\psi-\varphi)=v_{A} \cdot \sin ^{2}(\psi-\varphi) \\
\equiv v_{A}^{D}-v_{A} \cdot D
\end{array}\right.
$$

$$
D^{M}=\sin ^{2}(\psi-\varphi)
$$

It is obtained from here (from the dynamic kinematics) the expression of the dynamic coefficient DM of the reciprocating piston actuated mechanism (relation A26), observing that it is identical to the expression A21 where the dynamic coefficient was determined based on the dynamic calculation. This checks the uniqueness of the dynamic coefficient for the same mechanism operated in the same way. To complete this new theory, the dynamic coefficient of the piston crank shaft actuated by the crank (in compressor mode) is still to be determined.

Figure 23 shows the transmission of forces aligned with the forces, which occurs in the dynamic cinematics.

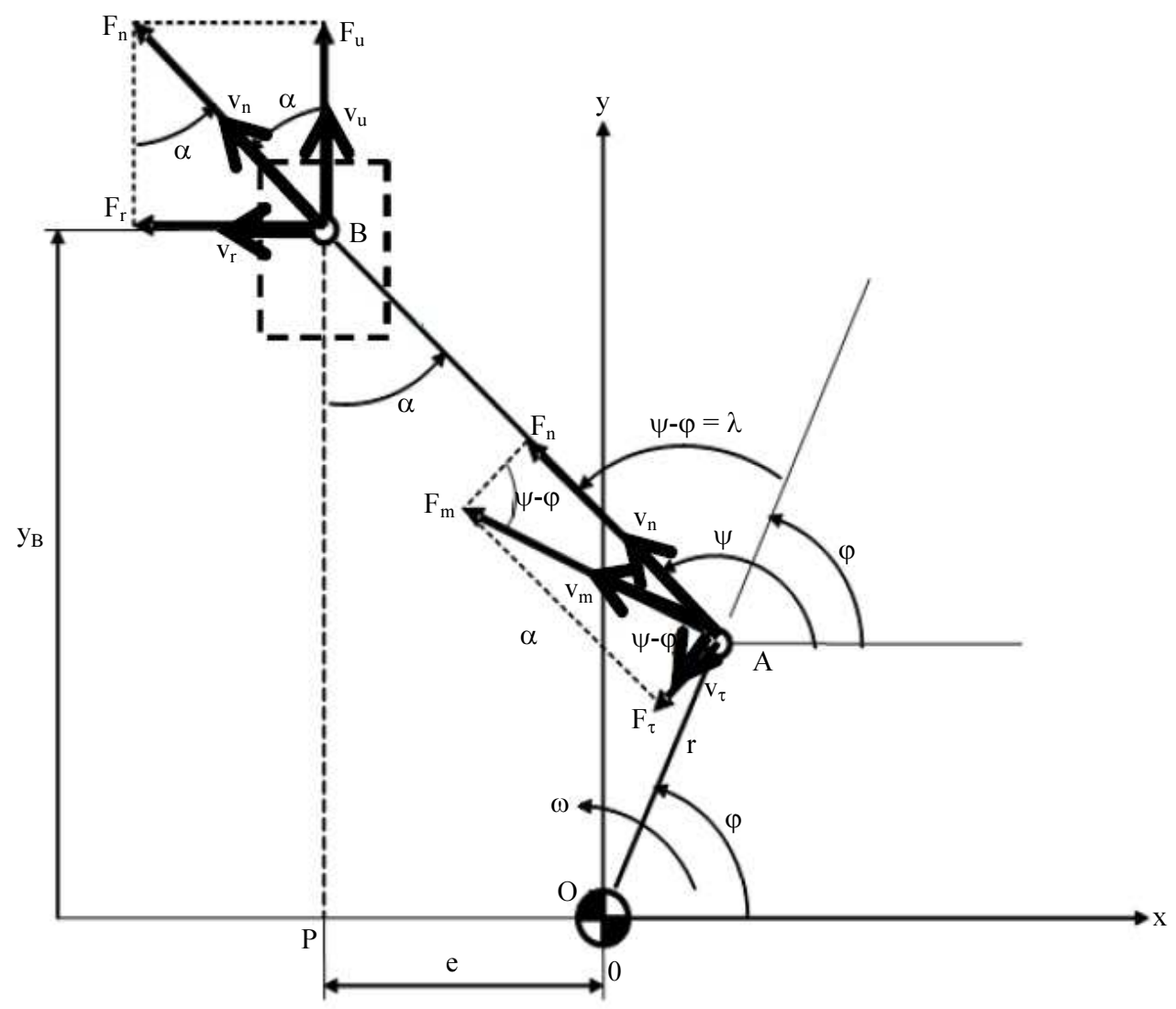

Fig. 23: Dynamic forces and speeds in a piston crank shaft system, when driven from the crank 
The inlet force Fm and the inlet velocity $v_{m}$ decompose generating the component along the line $F_{n}$ and $v_{n}$ respectively. Forces are the real forces acting on the mechanism and these cinematic-dynamic velocities are the natural ones that follow the trajectories (directions) imposed by the forces. Generally, they overlap and impose over known kinematic (static) velocities, which are calculated on the basis of the links imposed by the kinematic couple of the mechanism (depending on the kinematic chain). You can write for speeds A27:

$$
\left\{\begin{array}{l}
v_{B}=v_{A} \cdot \frac{\sin (\psi-\varphi)}{\sin \psi} ; v_{B}^{D}=v_{B} \cdot D^{C}=v_{A} \cdot \frac{\sin (\psi-\varphi)}{\sin \psi} \cdot D^{C} \\
v_{u}=v_{n} \cdot \cos \alpha=v_{n} \cdot \sin \psi=v_{m} \cdot \sin \psi \cdot \sin (\psi-\varphi) \\
=v_{A} \cdot \sin \psi \cdot \sin (\psi-\varphi) \\
v_{u}=v_{B}^{D} \Rightarrow v_{A} \cdot \sin \psi \cdot \sin (\psi-\varphi)=v_{A} \cdot \frac{\sin (\psi-\varphi)}{\sin \psi} \cdot D^{C} \\
\Rightarrow D^{C}=\sin ^{2} \psi
\end{array}\right.
$$

For forces, powers and yields, the following relationships are written (A28-A34):

$$
\begin{aligned}
& \left\{\begin{array}{l}
F_{n}=F_{m} \cdot \sin (\psi-\varphi) \\
F_{\tau}=F_{m} \cdot \cos (\psi-\varphi)
\end{array}\right. \\
& \left\{\begin{array}{l}
F_{u}=F_{n} \cdot \cos \alpha=F_{n} \cdot \sin \psi=F_{m} \cdot \sin (\psi-\varphi) \cdot \sin \psi \\
F_{r}=F_{n} \cdot \sin \alpha=-F_{n} \cdot \cos \psi=-F_{m} \cdot \sin (\psi-\varphi) \cdot \cos \psi
\end{array}\right. \\
& \left\{\begin{array}{l}
P_{u}=F_{u} \cdot v_{B}=F_{m} \cdot \sin (\psi-\varphi) \cdot \sin \psi \cdot \frac{r \cdot \omega \cdot \sin (\psi-\varphi)}{\sin \psi} \\
=F_{m} \cdot r \cdot \omega \cdot \sin ^{2}(\psi-\varphi)=F_{m} \cdot v_{A} \cdot \sin ^{2}(\psi-\varphi)
\end{array}\right. \\
& P_{c}=F_{m} \cdot v_{A}=F_{m} \cdot r \cdot \omega \\
& \eta_{i}=\frac{P_{u}}{P_{c}}=\frac{F_{m} \cdot v_{A} \cdot \sin ^{2}(\psi-\varphi)}{F_{m} \cdot v_{A}}=\sin ^{2}(\psi-\varphi) \\
& \left\{\begin{array}{l}
P_{u}^{D}=F_{u} \cdot v_{B}^{D} \\
=F_{m} \cdot \sin (\psi-\varphi) \cdot \sin \psi \cdot v_{A} \cdot \sin \psi \cdot \sin (\psi-\varphi)
\end{array}\right. \\
& \begin{array}{l}
=F_{m} \cdot r \cdot \omega \cdot \sin ^{2}(\psi-\varphi) \cdot \sin ^{2} \psi \\
=F \cdot v_{A} \cdot \sin ^{2}(\psi-\varphi) \cdot \sin ^{2} \psi
\end{array} \\
& \eta_{i}^{D C}=\frac{P_{u}^{D}}{P_{c}}=\frac{F_{m} \cdot v_{A} \cdot \sin ^{2} \psi \cdot \sin ^{2}(\psi-\varphi)}{F_{m} \cdot v_{A}} \\
& =\sin ^{2}(\psi-\varphi) \cdot \sin ^{2} \psi=\eta_{i} \cdot D^{C}
\end{aligned}
$$

The first conclusion that can be drawn is that the instantaneous dynamic mechanical efficiency (which is closer to the real mechanism) is less than the ordinary mechanical mechanics, because the dynamic yield is even the classic mechanical efficiency multiplied by the dynamic coefficient which being subunitarily results that the dynamic yield will be smaller or at most equal to the classic one.

In addition, the dynamic yield is the same for crank drive and piston engine actuation and will have the same value regardless of the drive type. The dynamic yield is practically uniform, but not all operating modes of the thermal motors are completely dynamic. This makes the Stirling engine or the two-stroke engine (Lenoir) real mechanical performance not much higher than the four-stroke Otto or Diesel engines. The higher the working speeds, the operating modes become almost completely dynamic.

Today, with high and very high working speeds, fourstroke internal combustion engines reach comparable performance to those of the Stirling engine or two-stroke engines. The more working regimes take place at higher speeds, the benefits of Stirling or Lenoir decrease.

Although the dynamic mechanical performance (closest to the real) is practically calculated with the same formula regardless of the drive type, the dynamic speeds and accelerations in the couplings differ depending on the drive mode, even for the same coupling.

Thus dynamic velocities (in the dynamic kinematics) of point B are calculated with relations A35.

Even if the output dynamically becomes uniform, the speeds and accelerations are more linear in the crank and sharper (and vibrational) drives during the piston stroke, so four-stroke internal combustion engines are more advantageous at this point view, followed by the twostroke (Lenoir), the last being the Stirling type engines:

$$
\left\{\begin{array}{l}
\text { Case } A-\text { withaction fromthe piston: } \\
D^{M}=\sin ^{2}(\psi-\varphi) ; \eta_{i}=\sin ^{2} \psi ; \text { regime Motor } \\
v_{B}^{D}=v_{B} \cdot D=v_{A} \cdot \frac{\sin (\psi-\varphi)}{\sin \psi} \cdot \sin ^{2}(\psi-\varphi) \\
=v_{A} \cdot \frac{\sin ^{3}(\psi-\varphi)}{\sin \psi} \\
v_{A}^{D}=v_{A} \cdot D=r \cdot \omega \cdot \sin ^{2}(\psi-\varphi) \\
\omega^{D}=\omega \cdot D=\omega \cdot \sin ^{2}(\psi-\varphi) \\
\text { Case } B-w i t h a c t i o n \text { fromthe crank } \\
D^{C}=\sin ^{2} \psi ; \eta_{i}=\sin ^{2}(\psi-\varphi) ; \text { regime Compressor } \\
v_{B}^{D}=v_{B} \cdot D=v_{A} \cdot \frac{\sin ^{2}(\psi-\varphi)}{\sin \psi} \cdot \sin ^{2} \psi \\
=v_{A} \cdot \sin ^{3}(\psi-\varphi) \cdot \sin \psi \\
v_{A}^{D}=v_{A} \cdot D=r \cdot \omega \cdot \sin ^{2} \psi \\
\omega^{D}=\omega \cdot D=\omega \cdot \sin ^{2} \psi
\end{array}\right.
$$

Dynamic accelerations are determined with relationships A36, in which the dynamic velocity relationship (appropriately arranged) is derived to obtain dynamic acceleration expression. 


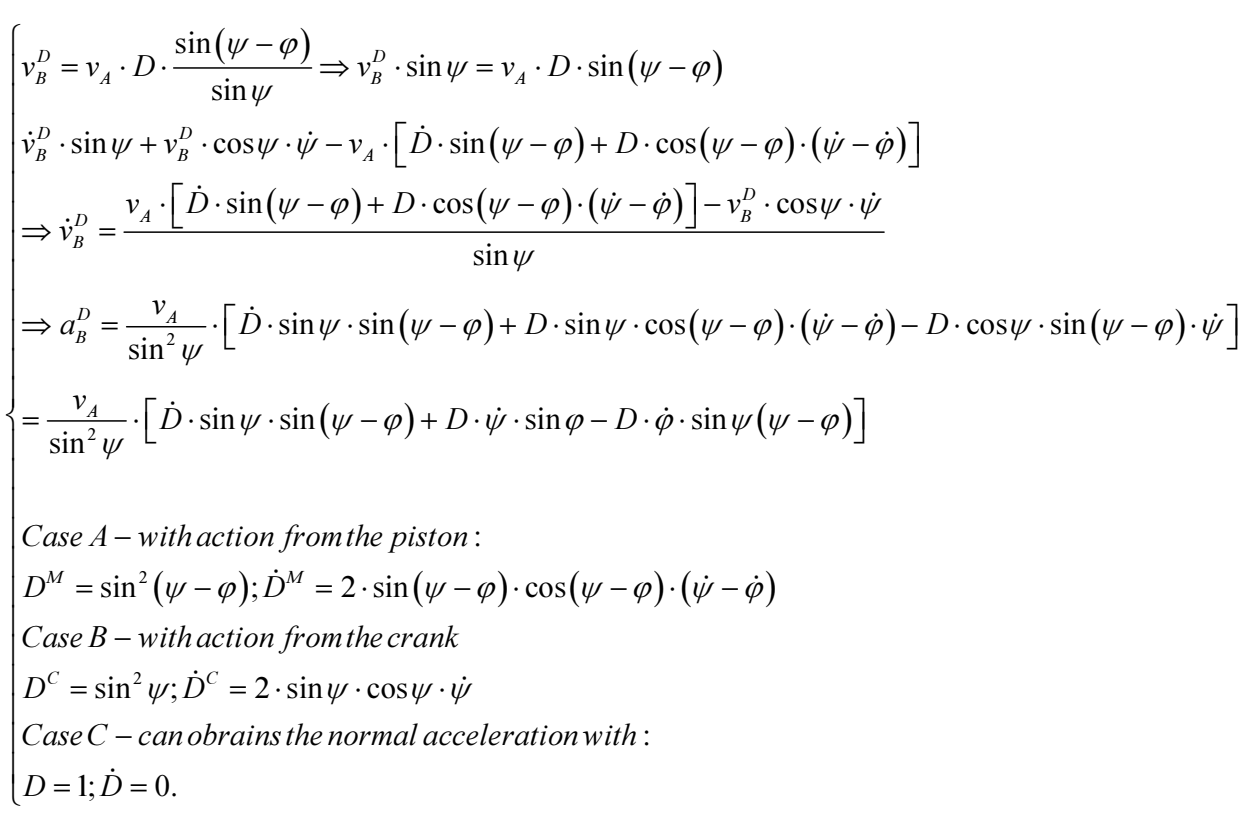

Through a calculation program, dynamic velocities and accelerations are determined for different types of thermal motors using relations (A35) and (A36).

Figures 24 and 25 are the two-stroke diagrams (Lenoir) in Fig. 24 being the dynamic speeds and in Fig. 25 the dynamic accelerations can be observed.

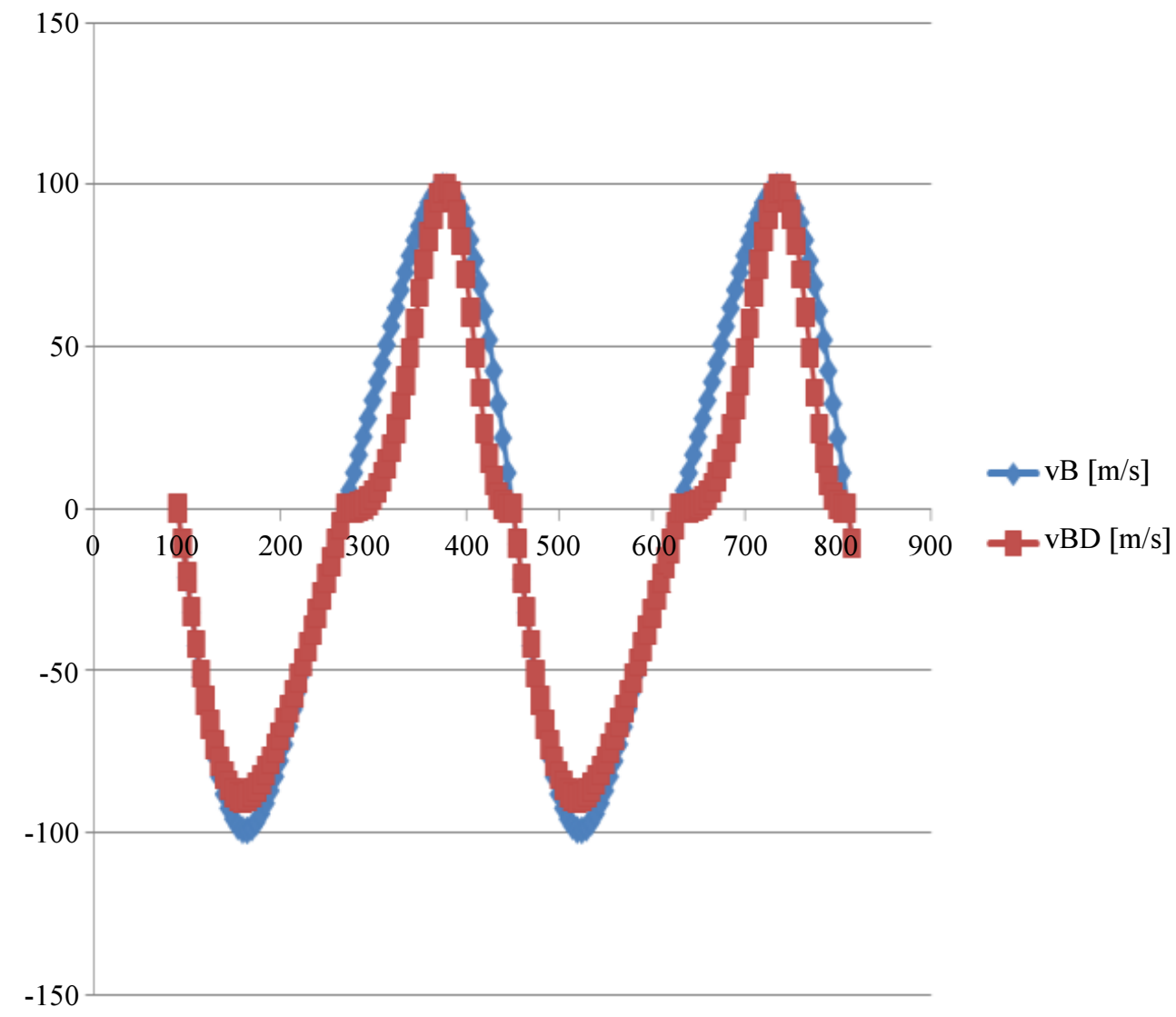

Fig. 24: Dynamic speeds on the Lenoir engine, two-stroke (with larger squares brown color) 


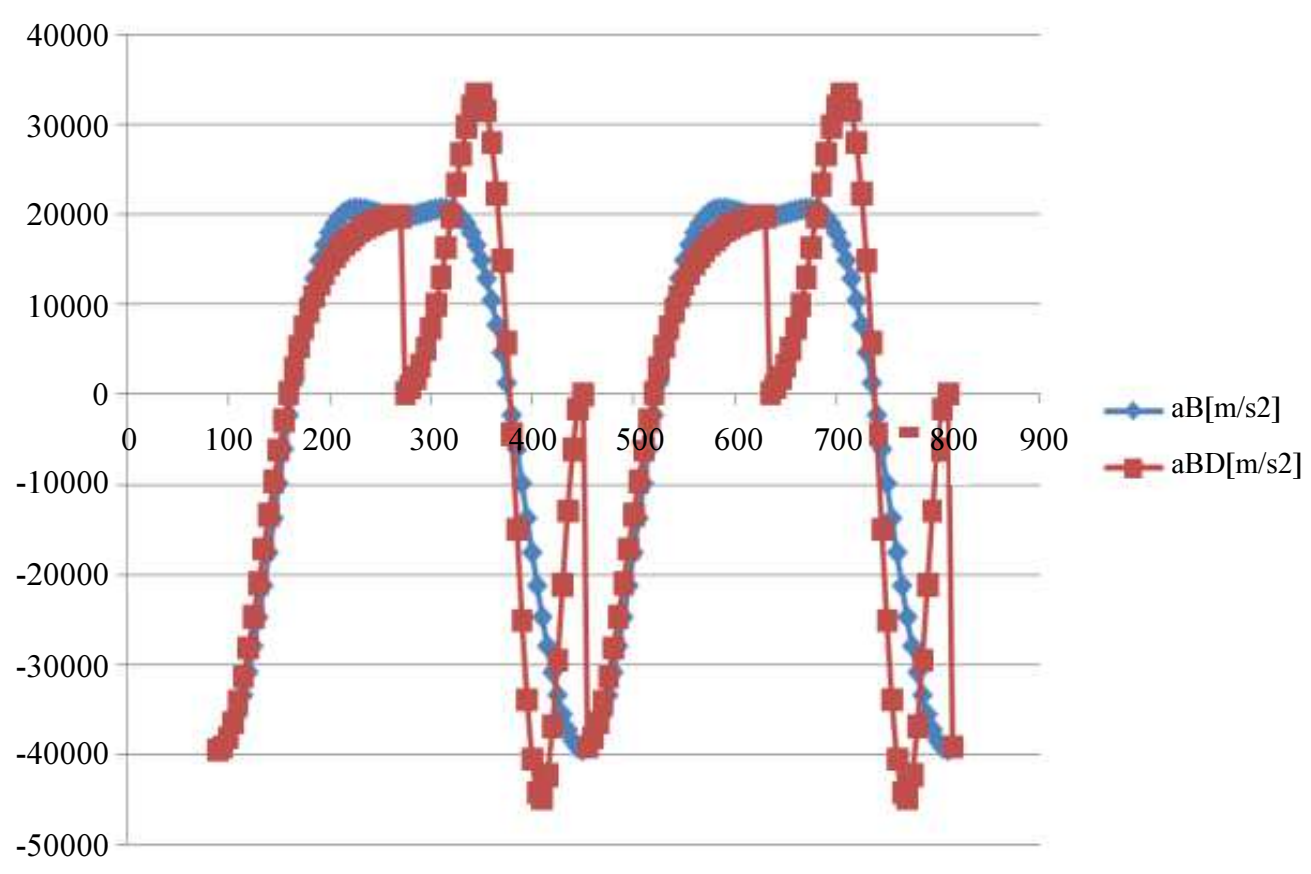

Fig. 25: Dynamic accelerations on the Lenoir engine, two-stroke (with larger squares brown color)

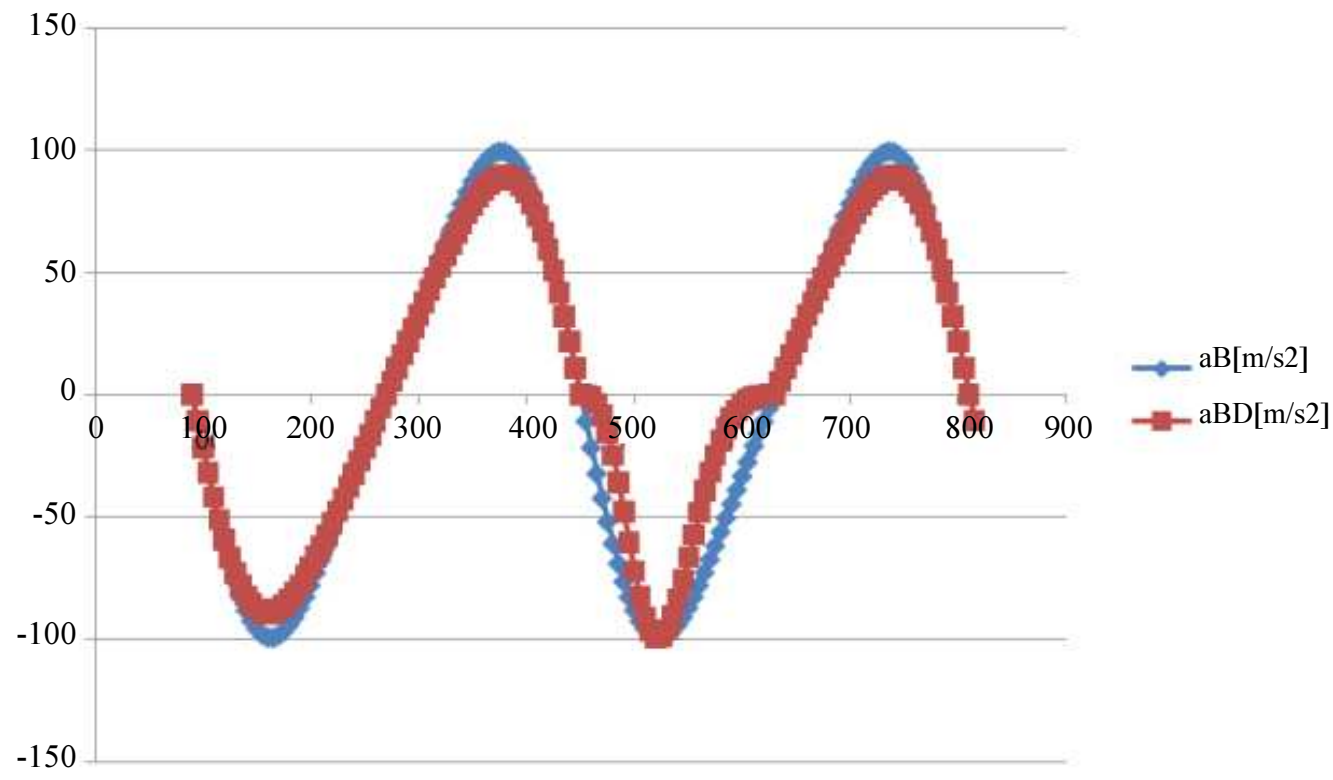

Fig. 26: Dynamic speeds on the four-stroke Otto (or Diesel) engine

In the four-stroke Otto (or Diesel) engine, the energy cycle no longer coincides with the kinematic, so only the fourth part of the entire energy cycle is the engine and only for it the dynamic speeds are shrunk (see below, see diagram in Fig. 26) and dynamic accelerations show shocks, vibrations and noises (follow the diagram in Fig. 27).

In the four-stroke Stirling engine, all times are engines, so the dynamic speeds are shrunk (thin, see the diagram in Fig. 28) and dynamic accelerations are shocks, vibrations and noises (follow the diagram in Fig. 29) throughout the range.

It is seen that the dynamic disadvantages of thermal motors are in fact a contradiction. The dynamics of their mechanisms is better at crank drive (from the crankshaft), but motor times (which have a lower dynamic kinematics) are virtually the ones needed, the only ones that produce the power (effectively) and which 
also generate high returns at the respective thermal engine; on the other hand, however, these motorways produce not only irregular operation with shocks, vibrations and noise on the thermal engine but also generate disadvantageous features. For this reason, the Stirling four-stroke engine and two phases with each active phase have the most power-and-load characteristic at the most disadvantageous speed.

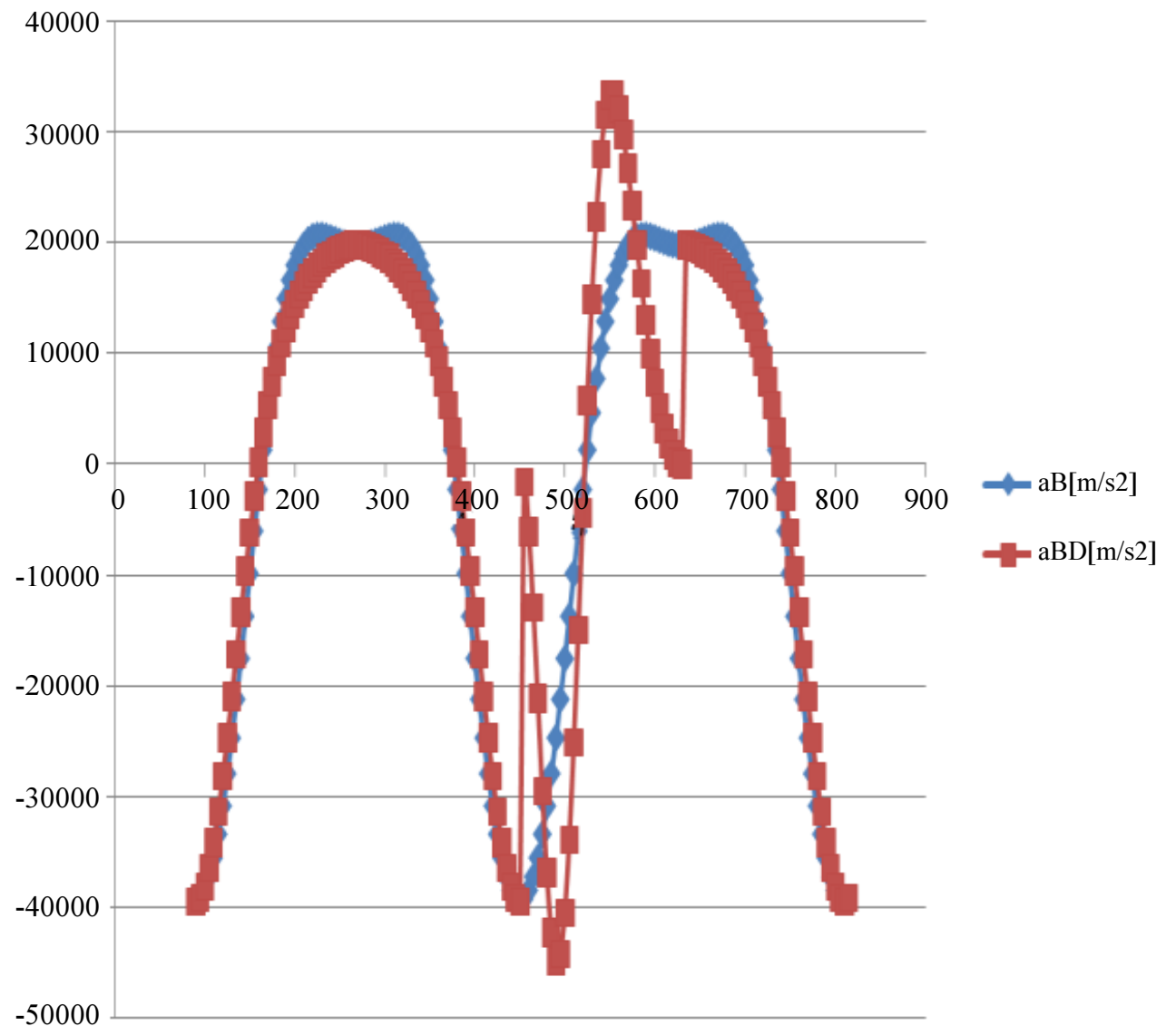

Fig. 27: Dynamic accelerations on the four-stroke Otto (or Diesel) engine

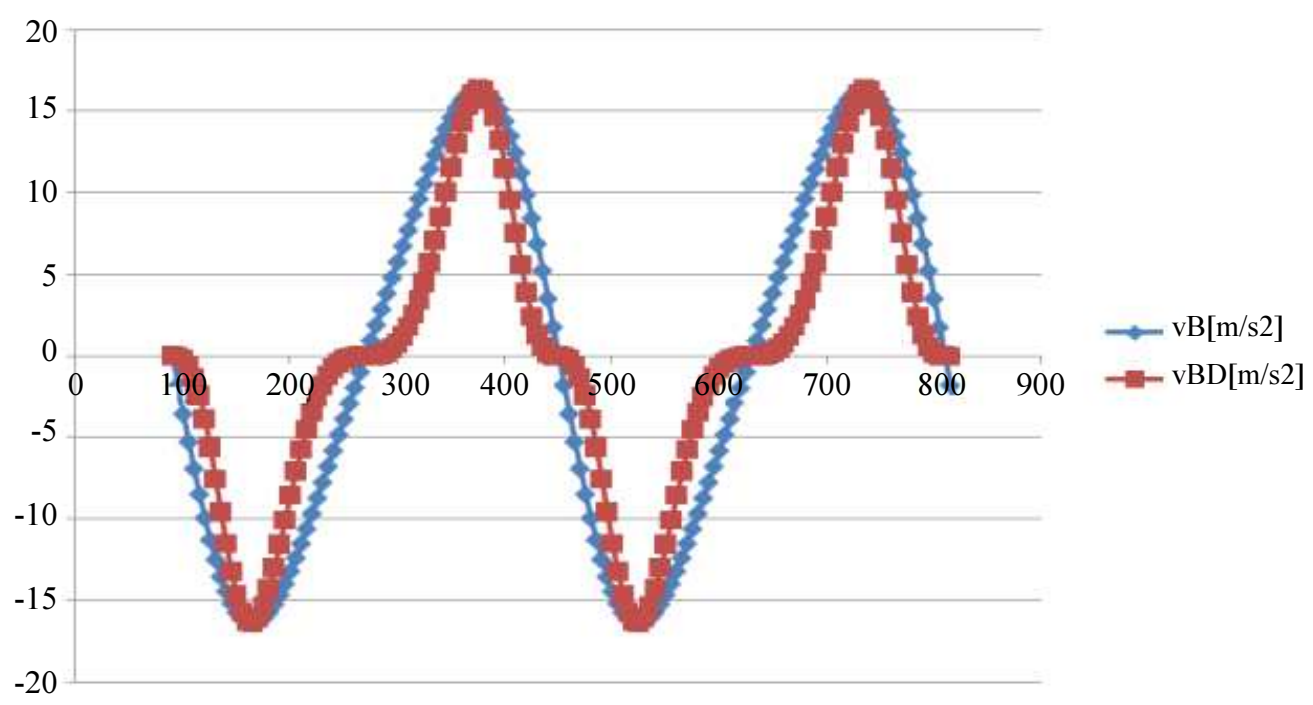

Fig. 28: Dynamic speeds in the Stirling four-stroke engine 


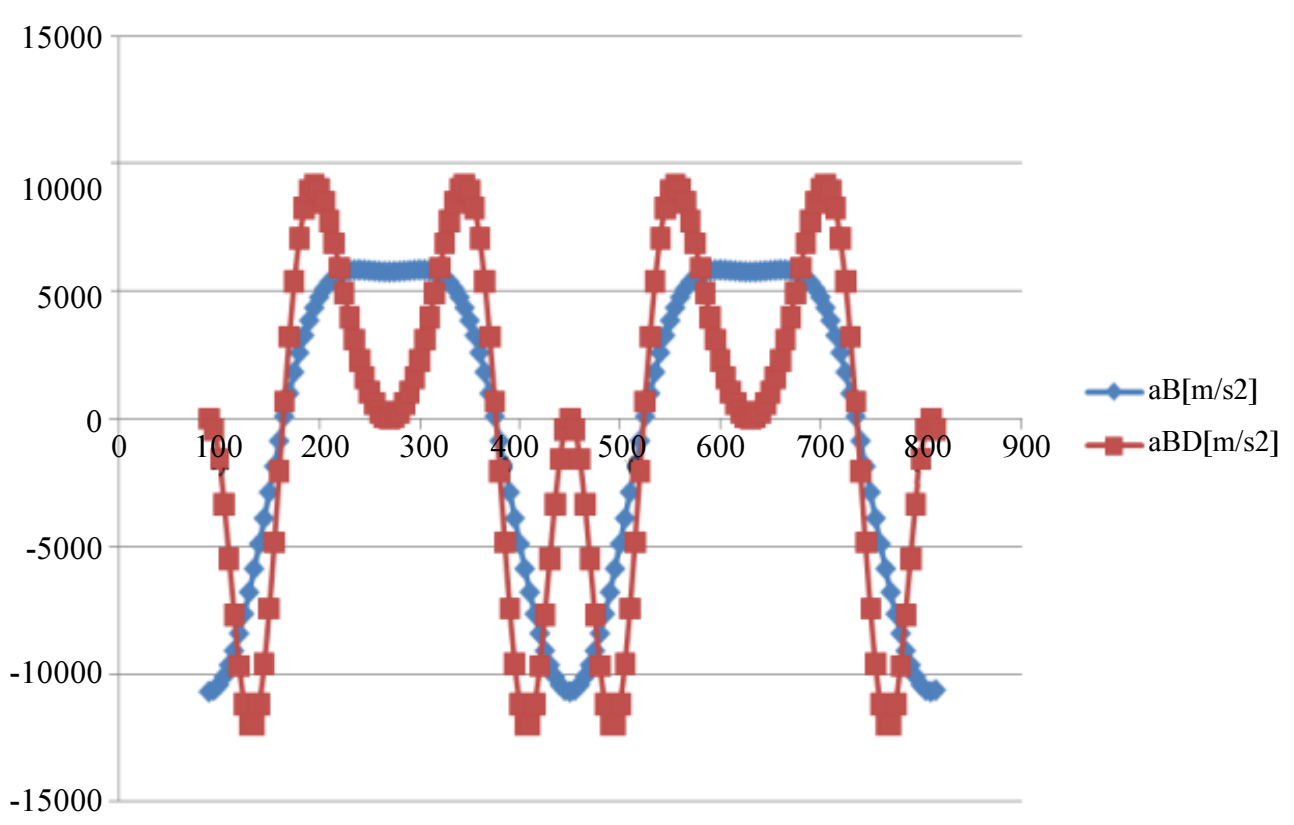

Fig. 29: Dynamic accelerations in the Stirling four-stroke engine

The two-stroke internal combustion engine does not have a very good feature and it also works with vibrations, vibrations and very large noises, which can overcome the known beatings of the four-stroke diesel engines, the traction being shocks (interruptions) even surpass those of the Stirling engines. The Lenoir engine does not make an engine brake, a vehicle equipped with a two-stroke thermal engine is overloaded (the brakes get too hot), the safety of the traffic being very low and the comfort of the passengers in the passenger compartment much diminished.

From this point of view, the four-stroke Otto or Diesel engines are the most advantageous, the first ones actually representing the highest version. For the Otto engines not to lose the advantage of fuel injection, many years ago, carburetors were dropped, Otto engines being gradually fueled by diesel fuel (keeps the ignition, because gasoline does not fire itself as it does diesel).

\section{Discussion}

In the process of transforming thermal energy into mechanical work, among the known thermal machines, the Stirling engine is the one that can achieve the highest yield (theoretically up to the maximum yield of the Carnot cycle), although in practice it is reduced by the properties of gas and materials used such as friction coefficient, thermal conductivity, melting point, breaking strength, plastic deformation, etc. This type of engine can operate on the basis of a heat source irrespective of its quality, whether it is solar, chemical, nuclear, biological, etc.
Unlike internal combustion engines, the Stirling engines can be economical, quieter, safer and less maintenance-free. They are preferred in specific applications where these advantages are reaped, especially if the main objective is not to minimize investment costs per unit of power (RON / $\mathrm{kW}$ ) but to those per unit of energy ( $\mathrm{RON} / \mathrm{kWh}$ ). Compared to internal combustion engines of a given power, the Stirling engines require higher capital expenditure, are larger and heavier, for which reason, viewed from this point of view, this technology is uncompetitive. For some applications, however, a sound analysis of the earnings-to-revenue ratio may favor Stirling engines versus internal combustion engines.

More recently, Stirling's benefits have become visible compared to rising energy costs, lack of energy resources and environmental issues such as climate change. Increasing interest in Stirling engine technology has spurred research and development in this area lately. Uses range from water pumping to astronautics and power generation based on rich sources of energy incompatible with internal combustion engines such as solar energy, or plant and animal scraps.

Another feature of the Stirling engines is their reversibility. Mechanically operated, they can act as heat pumps. Tests were conducted using wind energy to drive a Stirling cycle heat pump to heat and condition air for dwelling in cold weather.

Stirling engines today have different uses.

Stirling engines are especially used in natural, unfavorable environments, in isolated locations, etc. 
Powerful stationary or mobile generators are built today with the Stirling motors, which operate an electric generator, thus obtaining heat and electricity in isolated places.

In theory, any temperature difference will put into operation a Stirling engine. The heat source can be both the energy emitted by burning a fuel (which justifies using the term external combustion engine) as well as solar, geothermal, nuclear, or even biological origin, in which case the Stirling engine used can no longer be called external thermal combustion engine, but a heat engine with the use of an external power source. As we have already shown, it can work by using a thermal gradient.

This thermal gradient (temperature difference) can be considered in either direction (positive or negative) so that Stirling engines can function not only when the external source of temperature is warmer than the internal source (the environment) but also when it is more cold (than ambient temperature), using ice or snow for this purpose. The cold source appears in the place where cryogenic liquids or ice are used. In order to generate significant power at low temperature differences, it is necessary to transport large amounts of fluid through the external heat exchanger, which will cause additional losses and reduce cycle efficiency. Because the heat source and the working gas are separated by a heat exchanger, a wide range of heat sources including fuels or residual heat from other processes can be used. Since they do not come in contact with internal moving parts, the Stirling engine can also work with siloxane-containing biogas, without the danger of accumulating silicates that would damage components, as is the case with the internal combustion engine which would use the same type of fuel. Lubricant life is significantly higher than the internal combustion engine, which is another significant advantage of the Stirling engines compared to the internal combustion engine.

La "U.S. Department of Energy in Washington, NASA Glenn Research Center "(from Cleveland), a free piston engine (Stirling type) is being studied for a radioactive isotope generator. This device will use a plutonium-based heat source.

The "Los Alamos National Laboratory" developed a "Stirling Thermal Acoustic Wave Machine" without moving parts. This machine converts heat into acoustic power waves (quoted from the indicated source) "can be used directly in acoustic waves or chillers with impulse tubes to produce cold by means of a heat source without using moving parts, or (...) to generate power through a linear generator or other electroacoustic power transformer."

Obviously the Stirling engine is also used here to generate electricity and the heat that is used as a source of energy can be taken from various sources.

On the basis of this principle, we can today take over and transform the excessive heat that occurs day in surface sand in desert areas into electricity. The cold area is the sand from the greater depth, or even the air in the environment.

In the desert the temperature differences are higher because the surface sand gets very hot on the day.

Sahara with $9,000,000 \mathrm{~km}^{2}$ is the largest desert on earth. The Sahara comprises a third of Africa (roughly the surface of the United States of America, or 26 times the surface of Germany). This dry desert stretches from the Atlantic Ocean to the Red Sea, forming a trapezium with a length of east-west side of about 1,500-2,000 km and north-south with a base length of 4,500-5,5000 km . Most of the wilderness is rocky (Hamada) with gravel (Serir), the sandy beach (Erg) occupying a smaller area.

The name Sahara comes from the Arabic language "Sahara" which in tuareg dialect means "the sand desert". Another hypothesis is that the origin of the expression would be "sahraa" or "es-sah-ra" which means sterile, sterile. The Romans called the southern province of Carthage "Desert" (i.e., land uninhabited, abandoned). In the Middle Ages it was simply called the Great Desert and in the nineteenth century it was called the Sahara. Arabs call Sahara "Bahr bela ma" which would mean "Great without water".

The Sahara desert occupies almost entirely North Africa, extending $5630 \mathrm{~km}$ from west to east, from the Atlantic Ocean to the Red Sea and $1930 \mathrm{~km}$ from north to south, from the Atlas Mountains and the Mediterranean Sea up to in the area of savannah in the Sudan region.

In a narrow sense, it stretches to the east only to the Valley of the Nile; the desert from the East of the Nile to the Red Sea is known as the Arabian Desert.

Sahara occupies large parts of the states:

Morocco, Algeria, Tunisia, Libya, Egypt, Mauritania, Mali, Niger, Chad, Sudan and a small part of Senegal and Burkina Faso.

The climate is desert-tropical, with high average temperatures $\left(38^{\circ} \mathrm{C}\right)$, particularly hot and dry; the dominant wind all year round is the Pasat wind, a dry wind that brings rain. The wind and high temperature variations from day to night have led to the formation of the desert. In the winter, during the night the air temperature drops to -10 degrees, while the summer can reach during the day 58 degrees Celsius. Precipitation is reduced (20-200 mm/year) and very high daily diurnal heat $\left(30^{\circ} \mathrm{C}\right.$ in air and $70^{\circ} \mathrm{C}$ on the ground). The average January temperature is $+10^{\circ} \mathrm{C}$ and July $35^{\circ} \mathrm{C}$. Lack of permanent watercourses, the hydrographic network is represented by winds (drought channels) that fill with water during occasional rains.

The Sahara desert is a very energetic potential (especially the day in the warmer months of the year).

Here, daytime temperatures of the soil often reach 70 $\left[{ }^{\circ} \mathrm{C}\right]\left(343\left[{ }^{\circ} \mathrm{K}\right]\right)$, which would allow a Stirling engine to produce a Carnot energy yield of about $20-25 \%$, that is, a third or even half of the maximum efficiency with which these types of engines work normally. 
The soil/air temperature difference of $30-400 \mathrm{~m} / \mathrm{min}$ decreases the yield, but using the temperature difference between the surface soil and the depth of about 500, a satisfactory yield can be obtained.

An effective fitting of such high-powered Stirling engine to drive a high-frequency alternating current electric power generator could donate much more energy to the desert area during the day than solar systems (whether sand, gravel or rock) from which the engine is warm, overheating that will be done as well as in modern solar plants, through mirrors focused on that area; in this way the place that has to be a hot source will remain hot during the day (not influenced by the heat absorbed by the engine) and additionally not only will the hot zone be maintained but it will become even hotter, fact which will increase Carnot's engine output from $15-20 \%$ to much higher values, the higher the sand temperature will be.

This method allows you to get electricity (electric) on a daily basis in any season, so not only in the summer and it can also be practiced anywhere, leaving no need for a desert area.

By cogeneration, from a pre-existing energy source, usually an industrial process, with the help of an installation, in addition to the mechanical or electrical power delivered, heat is provided for heating. Normally the primary heat source is the entry for the Stirling engine heater and as such will have a higher temperature than the heat source for the heating application made up of the engine exhaust.

The power produced by the Stirling engine is often used in agriculture in various processes, resulting in biomass waste that in turn can be used as motor fuel to avoid the cost of transporting and storing waste. The process is generally abundant in energy resources being economically advantageous.

WhisperGen, based in Christchurch/New Zealand, has developed an AC Micro Combined Heat and Power co-generation based on the Stirling cycle. These microplants are methane-fueled heating systems that also supply electricity to the grid. WhisperGen announced in 2004 that it will produce 80000 homes of this type for UK housing. A batch of 20 plants started the test in Germany in 2006.

In nuclear power plants there is the possibility of using Stirling machines for power generation. By replacing the Stirling engine turbines, the complexity of the construction can be reduced, a higher yield can be achieved and radioactive waste can be reduced. Certain uranium enrichment reactors use liquid sodium as a cooling agent. If the thermal energy is still used in a steam plant, water/sodium heat exchangers are needed which increases the degree of danger due to the possibility of violent reaction of sodium with water in case of direct contact. Using the Stirling engine causes the water to be removed from the cycle.
US government laboratories have developed a modern Stirling engine under the name SRG (Stirling Radioisotope Generator) for use in space exploration. It is designed to generate electricity for spacecraft leaving the solar system with a life span of several decades.

This engine employs a single discharge piston (to reduce moving parts) and high energy acoustic waves for energy transfer. The heat source is a radioactive fuel block and the residual heat is eliminated in space. This assembly produces four times more energy from the same fuel block as compared to a similar radiator (RTG) type radiator (radiosotope thermoelectric generator).

Theoretically, Stirling engines would also have the advantage of being an airplane engine. They are quieter and less polluting, yields increase with altitude (internal combustion engine output decreases with altitude), are safer in operation due to fewer components, especially mobile components and lack of ignition, produce less vibration (structure of resistance will last longer), are more reliable and safer using less explosive fuel.

Kockums, the Swedish ship builder, constructed at least 8 Gotland submarines with Stirling drives in 1980.

In the automotive industry, the use of Stirling engines to drive cars is often argued by the power / weight ratio too low and a start-up time too long.

Alongside projects from Ford and American Motor Companies at NASA, at least two Stirling engines were built.

The bigger problems lie in the long start time, the slow response to acceleration, stop and load that has not been resolved immediately. Many believe that hybrid drive would eliminate these shortcomings, but for the time being, no vehicle has been built on this basis.

The vehicles designed at NASA were called MOD I and MOD II. In the case of MOD II, a normal spark ignition engine was replaced by a 4-door Chevrolet Celebrity hatchback in 1985.

In the report published in 1986, Annex A states that consumption on both the highway and the city has decreased for the average car from $5.88 \mathrm{~L} / 100 \mathrm{~km}$ to $4.05 \mathrm{~L} / 100 \mathrm{~km}$ and for the high-capacity car from 9.05 $\mathrm{L} / 100 \mathrm{~km}$ to $7.13 \mathrm{~L} / 100 \mathrm{~km}$.

The start time of the NASA vehicle was 30 seconds, while the Ford pilot car using an electric preheater in the hot air area managed to start in just a few seconds.

\section{Conclusions}

The most common external combustion engines were steam engines. Although initially used as a naval engine, the emergence and development of steam engines (as well as the first cam mechanism) are closely related to the emergence and development of tissue wounds (automatic tissue machines). 
Today, stirring thermal combustion engines complement and even replace steam engines, but in large part those with internal combustion.

Most uses, stirling engines, have them in vehicles and road, land and marine vehicles, but also within modern energy systems.

Because the stirling engines started harder and less adapted to the car-load feature of a car, initially the stirring engines were introduced on adaptive cars, or together with an internal combustion engine (diesel or Otto) under the form of hybrid engines, or more recently with an electric motor.

Along with an internal combustion engine, the stirring engine greatly increases the efficiency of the hybrid system, because it even works with the heat dissipated by the diesel engine or Otto, that is, cooling the internal combustion engine is not done by dissipating (heat loss) but all the thermal energy (which is in the form of heat) that has to lose the internal combustion engine will be the warm source of the stirling engine and instead of losing it, it will act effectively on the stirling engine, thus greatly enhancing the efficiency of the system.

In green, sustainable, renewable, clean and friendly energy, stirling engines are mainly used in two ways:

- Like a power generator in solar farms, where all the redesigned and concentrated heat from the sun, lots of parabolic mirrors, heat concentrated on a huge boiler with water or oil, is used to heat the boiler, which is the source constantly warming the stirring engine, effectively acting it and it still rotates a very high current generator

- Or as a motor positioned in the glare of a huge parabolic mirror, acting constantly on the mirror, rotating it in all directions so that it can permanently capture as much solar energy as possible

In addition to vehicles and green energy, stirring engines are still used since their appearance in power groups, stationary or portable power generators, hospitals, military units and so on.

Today the conquest of space is done through robotization, automation, with modern, fast, autonomous spacecraft, with many capabilities, but also with stirling generators (Petrescu et al., 2017k; 2017l; 2017m; 2017n; 2017o; 2017p; 2017q; 2017r; 2017s; 2017t; 2017u; 2017v; 2017w; 2017x; 2017y; 2017z; 2017aa; 2017ab; 2017ac; 2017ad; 2017ae).

The operation of a main mechanism of a stirling engine is basically similar to internal combustion heat engines, with the exception that all times are engines. From this point of view, the mechanical efficiency of a stirring engine has the advantage of being greatly increased compared to internal combustion engines, all times being active, provided that the heat output of the stirring engine can be raised from the design (by using a warm source at a minimum of 900 degrees).

A stirling engine uses to operate a temperature gradient, so any difference between the ambient temperature and the source used can cause a stirring engine to work. You can use high temperatures (hot source), or low (a cold source). The working principle of an external combustion heat engine is similar to that of the refrigerator, but it is reversed.

\section{Acknowledgment}

The work was appreciated by Professor Aniello Riccio SECONDA UNIVERSITA' DEGLI STUDI DI NAPOLI Italy and Dr. (Ms.) Shweta Agarwala Senior Research Scientist at Singapore Center for 3D Printing Nanyang Technological University Singapore, whom we thanks and in this way.

\section{Funding Information}

Research contract: Contract number $36-5-4 D / 1986$ from 24IV1985, beneficiary CNST RO (Romanian National Center for Science and Technology) Improving dynamic mechanisms internal combustion engines.

Preliminary Contract from 2010-03-13 with: BMW Group Germany

Virtuelle Innovations-Agentur (VIA)

Knorrstraße 147

D-80788 München

http://www.bmwgroup.com/

Bayerische Motoren Werke Aktiengesellschaft Vorstand: Norbert Reithofer, Vorsitzender, Frank-Peter Arndt, Herbert Diess, Klaus Draeger, Friedrich Eichiner, Harald Krüger, Ian Robertson Vorsitzender des Aufsichtsrats: Joachim Milberg Sitz und Registergericht: München HRB 42243

Preliminary Contract from 2010-03-13 with: Mercedes Benz Daimler AG, Germany

All these matters are copyrighted.

Copyrights: 398-tDGpbsxgrD, from 18-02-2010 01:16:36 and 394-qodGnhhtej, from 17-02-2010 13:42:18.

\section{Ethics}

This article is original. Authors declare that are not ethical issues that may arise after the publication of this manuscript.

\section{References}

Antonescu, P., 2000. Mechanisms and Handlers. 1st Edn., Printech Publishing House, Bucharest. 
Antonescu, P. and F. Petrescu, 1985. Analytical method of synthesis of cam mechanism and flat stick. Proceedings of the 4th International Symposium on Mechanism Theory and Practice, (TPM' 85), Bucharest.

Antonescu, P. and F. Petrescu, 1989. Contributions to cinetoelastodynamic analysis of distribution mechanisms. Bucharest.

Antonescu, P., M. Oprean and F. Petrescu, 1985a. Contributions to the synthesis of oscillating cam mechanism and oscillating flat stick. Proceedings of the 4th International Symposium on Theory and Practice of Mechanisms, (TPM' 85), Bucharest.

Antonescu, P., M. Oprean and F. Petrescu, 1985b. At the projection of the oscillante cams, there are mechanisms and distribution variables. Proceedings of the 5th Conference for Engines, Automobiles, Tractors and Agricultural Machines, I-Engines and Automobiles, (AMA' 85), Brasov.

Antonescu, P., M. Oprean and F. Petrescu, 1986. Projection of the profile of the rotating camshaft acting on the oscillating plate with disengagement. Proceedings of the 3rd National Computer Assisted Designing Symposium in Mechanisms and Machine Bodies, (MOM' 86), Brasov.

Antonescu, P., M. Oprean and F. Petrescu, 1987. Dynamic analysis of the cam distribution mechanisms. Proceedings of the 7 th National Symposium of Industrial Robots and Spatial Mechanisms, (IMS' 87), Bucharest.

Antonescu, P., M. Oprean and F. Petrescu, 1988. Analytical synthesis of Kurz profile, rotating flat cam cam. Machine Build. Rev. Bucharest.

Antonescu, P., F. Petrescu and O. Antonescu, 1994. Contributions to the synthesis of the rotating cam mechanism and the tip of the balancing tip. Brasov.

Antonescu, P., F. Petrescu and D. Antonescu, 1997. Geometrical synthesis of the rotary cam and balance tappet mechanism. Bucharest.

Antonescu, P., F. Petrescu and O. Antonescu, 2000a. Contributions to the synthesis of the rotary disc-cam profile. Proceedings of the 8th International Conference on Theory of Machines and Mechanisms, (TMM' 00), Liberec, Czech Republic, pp: 51-56.

Antonescu, P., F. Petrescu and O. Antonescu, $2000 \mathrm{~b}$. Synthesis of the rotary cam profile with balance follower. Proceedings of the 8th Symposium on Mechanisms and Mechanical Transmissions, (MMT' 000), Timişoara, pp: 39-44.

Antonescu, P., F. Petrescu and O. Antonescu, 2001. Contributions to the synthesis of mechanisms with rotary disc-cam. Proceedings of the 8th IFToMM International Symposium on Theory of Machines and Mechanisms, (TMM' 01), Bucharest, ROMANIA, pp: 31-36.
Aversa, R., R.V. Petrescu, A. Apicella and F.I.T. Petrescu, 2017a. Nano-diamond hybrid materials for structural biomedical application. Am. J. Biochem. Biotechnol., 13: 34-41. DOI: 10.3844/ajbbsp.2017.34.41

Aversa, R., R.V. Petrescu, B. Akash, R.B. Bucinell and J.M. Corchado et al., 2017b. Kinematics and forces to a new model forging manipulator. Am. J. Applied Sci., 14: 60-80. DOI: 10.3844/ajassp.2017.60.80

Aversa, R., R.V. Petrescu, A. Apicella, F.I.T. Petrescu and J.K. Calautit et al., 2017c. Something about the $\mathrm{V}$ engines design. Am. J. Applied Sci., 14: 34-52. DOI: 10.3844/ajassp.2017.34.52

Aversa, R., D. Parcesepe, R.V. Petrescu, F. Berto and G. Chen et al., 2017d. Processability of bulk metallic glasses. Am. J. Applied Sci., 14: 294-301. DOI: 10.3844/ajassp.2017.294.301

Aversa, R., R.V. Petrescu, A. Apicella and F.I.T. Petrescu, 2017e. Modern transportation and photovoltaic energy for urban ecotourism. Transylvanian Rev. Admin. Sci., 13: 5-20. DOI: 10.24193/tras.SI2017.1

Aversa, R., F.I.T. Petrescu, R.V. Petrescu and A. Apicella, 2016a. Biomimetic FEA bone modeling for customized hybrid biological prostheses development. Am. J. Applied Sci., 13: 1060-1067. DOI: 10.3844/ajassp.2016.1060.1067

Aversa, R., D. Parcesepe, R.V. Petrescu, G. Chen and F.I.T. Petrescu et al., 2016b. Glassy amorphous metal injection molded induced morphological defects. Am. J. Applied Sci., 13: 1476-1482. DOI: 10.3844 ajassp.2016.1476.1482

Aversa, R., R.V. Petrescu, F.I.T. Petrescu and A. Apicella, 2016c. Smart-factory: Optimization and process control of composite centrifuged pipes. Am. J. Applied Sci., 13: 1330-1341.

DOI: 10.3844/ajassp.2016.1330.1341

Aversa, R., F. Tamburrino, R.V. Petrescu, F.I.T. Petrescu and M. Artur et al., $2016 \mathrm{~d}$. Biomechanically inspired shape memory effect machines driven by muscle like acting NiTi alloys. Am. J. Applied Sci., 13: 1264-1271. DOI: 10.3844/ajassp.2016.1264.1271

Cao, W., H. Ding, Z. Bin and C. Ziming, 2013. New structural representation and digital-analysis platform for symmetrical parallel mechanisms. Int. J. Adv. Robot. Syst. DOI: 10.5772/56380

Cataldo, R., 2006 Overview of planetary power system options for education. ITEA Human Exploration Project Authors, at Glenn Research Center. Brooke Park, $\mathrm{OH}$.

Cayley George, From Wikipedia. The free encyclopedia. https://en.wikipedia.org/wiki/George_Cayley

Chen, J. and R.J. Patton, 1999. Robust Model-Based Fault Diagnosis for Dynamic Systems. 1st Edn., Kluwer Academic Publisher, Boston, ISBN-10: 0792384113 , pp: 356. 
Clément, A., From Wikipedia. The free encyclopedia. https://en.wikipedia.org/wiki/Cl\%C3\%A9ment_Ader

Coandă-1910, From Wikipedia. The free encyclopedia. https://en.wikipedia.org/wiki/Coand\%C4\%83-1910

Comănescu, A., D. Comănescu, I. Dugăeşescu and A. Boureci, 2010. The Basics of Modeling Mechanisms. 1st Edn., Politehnica Press Publishing House, Bucharest, ISBN-10: 978-606-515-115-4, pp: 274.

Crickmore, P.F., 1997. Lockheed's blackbirds-A-12, YF12 and SR-71A. Wings Fame, 8: 30-93.

Donald, D., 2003. Lockheed's blackbirds: A-12, YF-12 and SR-71". Black Jets. AIRtime.

Dong, H., N. Giakoumidis, N. Figueroa and N. Mavridis, 2013. Approaching behaviour monitor and vibration indication in developing a General Moving Object Alarm System (GMOAS). Int. J. Adv. Robot. Sys. DOI: $10.5772 / 56586$

Droste, J., 1915. On the field of a single centre in Einstein's theory of gravitation. Koninklijke Nederlandsche Akademie van Wetenschappen Proc., 17: 998-1011.

De Melo, L.F., S.F. Rosário and J.M., Rosário, 2012. Mobile robot navigation modelling, control and applications. Int. Rev. Modell. Simulat., 5: 10591068.

Fawcett, G.F. and J.N. Fawcett, 1974. Comparison of Polydyne and Non Polydyne Cams. In: Cams and Cam Mechanisms, Rees Joned, J. (Ed.), MEP, London and Birmingham, Alabama.

Fernandez, V., F. Luis, L.F. Penin, J. Araujo and A. Caramagno, 2005. Modeling and FDI specification of a RLV Re-entry for robust estimation of sensor and actuator faults. Proceedings of the AIAA Guidance, Navigation and Control Conference and Exhibit, Aug. 15-18, San Francisco. DOI: $10.2514 / 6.2005-6254$

Finkelstein, D., 1958. Past-future asymmetry of the gravitational field of a point particle. Phys. Rev., 110: 965-967.

Fonod, R., D. Henry, C. Charbonnel and E. Bornschlegl et al., 2015. Position and attitude model-based thruster fault diagnosis: A comparison study. J. Guidance Control Dynam., 38: 1012-1026. DOI: 10.2514/1.G000309

Frățilă, G., M. Frățilă and S. Samoilă, 2011. Automobiles, Construction, Exploitation, Reparation. 10th Edn., EDP, Bucharest, ISBN-13: 978-973-30-2857-4.

Garcia, E., M.A. Jimenez, P.G. De Santos and M. Armada, 2007. The evolution of robotics research. IEEE Robot. Autom. Magaz., 14: 90-103. DOI: 10.1109/MRA.2007.339608

Garcia-Murillo, M., J. Gallardo-Alvarado and E. Castillo-Castaneda, 2013. Finding the generalized forces of a series-parallel manipulator. IJARS. DOI: $10.5772 / 53824$
Goddard, 1916. Rocket apparatus patent. Smithsonian Institution Archives.

Goodall, J., 2003. Lockheed's SR-71 "Blackbird" Family. 1st Edn., Aerofax/Midland Publishing, Hinckley, UK, ISBN-10: 1-85780-138-5.

Gorder, P.F., 2015. What's on the surface of a black hole? Not a "firewall" - and the nature of the universe depends on it, a physicist explains.

Graham, R.H., 2002. SR-71 Blackbird: Stories, Tales and Legends. 1st Edn., Zenith Imprint, North Branch, Minnesota, ISBN-10: 1610607503.

Gruener, J.E., 2006. Lunar exploration (Presentation to ITEA Human Exploration Project Authors, Johnson Space Center). Houston, TX.

Gunston, B., 2010. Airbus: The Complete Story. 1st Edn., Haynes Publishing UK, Sparkford, ISBN-10: 1844255859, pp: 288.

Grunwald, B., 1980. Theory, Calculation and Construction of Motor Vehicles for Road Vehicles. 1st Edn., Didactic and Pedagogical Publishing House, Bucharest.

Hargreaves, C.M., 1991. The Philips Stirling Engine. 1st Edn., Elsevier Publishers, ISBN-10: 0-444-88463-7.

He, B., Z. Wang, Q. Li, H. Xie and R. Shen, 2013. An analytic method for the kinematics and dynamics of a multiple-backbone continuum robot. IJARS. DOI: $10.5772 / 54051$

Hewish, A., 1970. Pulsars. Ann. Rev. Astronomy Astrophys., 8: 265-296.

Homețescu, C.A., 2003. Introduction to stirling machines. 1st Edn., CERMI Publishing House, Iaşi.

Jenkins, D.R., 2001. Lockheed Secret Projects: Inside the Skunk Works. 1st Edn., Zenith Imprint, St. Paul, Minnesota: MBI Publishing Company, ISBN-10: 1610607287.

Jones, J.R. and J.E. Reeve, 1974. Dynamic Response of Cam Curves Based on Sinusoidal Segments. In: Cams and Cam Mechanisms, Rees Jones, J. (Ed.), London and Birmingham, Alabama.

Kaufman, H.R., 1959. Installations at NASA Glenn.

Koster, M.P., 1974. The Effects of Backlash and Shaft Flexibility on the Dynamic Behavior of a Cam Mechanism. In: Cams and Cam Mechanisms, Rees Jones, J. (Ed.), London and Birmingham, Alabama, pp: 141-146.

Laming, T., 2000. Airbus A320. 1st Edn., Zenith Press.

Landis, T.R. and D.R. Jenkins, 2005. Lockheed Blackbirds. 1st Edn., Specialty Press, North Branch, ISBN-10: 1580070868, pp: 104.

Larson, G.C., 2015. Electrical power will change the look of aviation. Air and Space Magazine. https:/www.airspacemag.com/flight-today/NASAelectric-propulsion-180957302/ 
Lee, B.J., 2013. Geometrical derivation of differential kinematics to calibrate model parameters of flexible manipulator. Int. J. Adv. Robot. Sys.

DOI: $10.5772 / 55592$

Lin, W., B. Li, X. Yang and D. Zhang, 2013. Modelling and control of inverse dynamics for a 5-DOF parallel kinematic polishing machine. Int. J. Adv. Robot. Sys. DOI: 10.5772/54966

List the first flights, From Wikipedia, free encyclopedia. https://ro.wikipedia.org/wiki/List $\% \mathrm{C} 4 \% 83$ cu prim ele zboruri

Liu, H., W. Zhou, X. Lai and S. Zhu, 2013. An efficient inverse kinematic algorithm for a PUMA560structured robot manipulator. IJARS. DOI: $10.5772 / 56403$

Lu, P., L. Van Eykeren, E. van Kampen and Q. P. Chu, 2015. Selective-reinitialization multiple-model adaptive estimation for fault detection and diagnosis. J. Guidance Control Dynam., 38: 14091424. DOI: $10.2514 / 1 . G 000587$

Lu, P., L. Van Eykeren, E. van Kampen, C.C. de Visser and Q.P. Chu, 2016. Adaptive three-step kalman filter for air data sensor fault detection and diagnosis. J. Guidance Control Dynam., 39: 590-604. DOI: $10.2514 / 1 . G 001313$

Martini, W., 1978. Stirling engine design manual, NASA-CR-135382. NASA.

Michell, J., 1784. On the means of discovering the distance, magnitude and c. of the fixed stars, in consequence of the diminution of the velocity of their light, in case such a diminution should be found to take place in any of them and such other data should be procured from observations, as would be farther necessary for that purpose. Philosophical Trans. Royal Society, 74: 35-57.

Mirsayar, M.M., V.A. Joneidi, R.V. Petrescu, F.I.T. Petrescu and F. Berto, 2017. Extended MTSN criterion for fracture analysis of soda lime glass. Eng. Fracture Mechan., 178: 50-59.

DOI: 10.1016/j.engfracmech.2017.04.018

Murray, K., A. Marcos and L.F. Penin, 2010. Development and testing of a GNC-FDI filter for a reusable launch vehicle during ascent. Proceedings of the AIAA Guidance, Navigation and Control Conference, Aug. 2-5, Toronto, Ontario Canada. DOI: $10.2514 / 6.2010-8195$

Norris, G., 2010. Airbus A380: Superjumbo of the 21st Century. 1st Edn., Zenith Press.

Oberth, H., 1955. They come from outer space. Fly. Saucer Rev., 1: 12-14.

Oppenheimer, J.R. and G.M. Volkoff, 1939. On massive neutron cores. Phys. Rev., 55: 374-381.

Padula, F. and V. Perdereau, 2013. An on-line path planner for industrial manipulators. Int. J. Adv. Robot. Sys. DOI: 10.5772/55063
Palumbo, R., G. Morani, M. De Stefano Fumo, C. Richiello and M. Di Donato et al., 2012. Concept study of an atmospheric reentry using a winged unmanned space vehicle. Proceedings of the 18th AIAA/3AF International Space Planes and Hypersonic Systems and Technologies Conference, Sept. 24-28, Tours, France.

DOI: $10.2514 / 6.2012-5857$

Patre, P. and S.M. Joshi, 2011. Accommodating sensor bias in MRAC for state tracking. Proceedings of the AIAA Guidance, Navigation and Control Conference, Aug. 8-11, Portland, Oregon. DOI: $10.2514 / 6.2011-6605$

Pelecudi, C., 1967. The Basics of Mechanism Analysis. Publishing house: Academy of the People's Republic of Romania.

Perumaal, S. and N. Jawahar, 2013. Automated trajectory planner of industrial robot for pick-andplace task. IJARS. DOI: 10.5772/53940

Petrescu, F. and R. Petrescu, 1995a. Contributions to optimization of the polynomial motion laws of the stick from the internal combustion engine distribution mechanism. Bucharest.

Petrescu, F. and R. Petrescu, 1995b. Contributions to the synthesis of internal combustion engine distribution mechanisms. Bucharest.

Petrescu, F. and R. Petrescu, 1997a. Dynamics of cam mechanisms (exemplified on the classic distribution mechanism). Bucharest.

Petrescu, F. and R. Petrescu, 1997b. Contributions to the synthesis of the distribution mechanisms of internal combustion engines with Cartesian coordinate method. Bucharest.

Petrescu, F. and R. Petrescu, 1997c. Contributions to maximizing polynomial laws for the active stroke of the distribution mechanism from internal combustion engines. Bucharest.

Petrescu, F. and R. Petrescu, 2000a. Synthesis of distribution mechanisms by the rectangular (cartesian) coordinate method. University of Craiova, Craiova.

Petrescu, F. and R. Petrescu, 2000b. The design (synthesis) of cams using the polar coordinate method (the triangle method). University of Craiova, Craiova.

Petrescu, F. and R. Petrescu, 2002a. Motion laws for cams. Proceedings of the 7th National Symposium with International Participation Computer Assisted Design, (PAC' 02), Braşov, pp: 321-326.

Petrescu, F. and R. Petrescu, 2002b. Camshaft dynamics elements. Proceedings of the 7th National Symposium with International Participation Computer Assisted Design, (PAC' 02), Braşov, pp: 327-332. 
Petrescu, F. and R. Petrescu, 2003. Some elements regarding the improvement of the engine design. Proceedings of the 8th National Symposium, Descriptive Geometry, Technical Graphics and Design, (GTD’ 03), Braşov, pp: 353-358.

Petrescu, F. and R. Petrescu, 2005a. The cam design for a better efficiency. Proceedings of the International Conference on Engineering Graphics and Design, (EGD' 05), Bucharest, pp: 245-248.

Petrescu, F. and R. Petrescu, 2005b. Contributions at the dynamics of cams. Proceedings of the 9th IFToMM International Symposium on Theory of Machines and Mechanisms, (TMM' 05), Bucharest, Romania, pp: 123-128.

Petrescu, F. and R. Petrescu, 2005c. Determining the dynamic efficiency of cams. Proceedings of the 9th IFToMM International Symposium on Theory of Machines and Mechanisms, (TMM' 05), Bucharest, Romania, pp: 129-134.

Petrescu, F. and R. Petrescu, 2005d. An original internal combustion engine. Proceedings of the 9th IFToMM International Symposium on Theory of Machines and Mechanisms, (TMM' 05), Bucharest, Romania, pp: 135-140.

Petrescu, F. and R. Petrescu, 2005e. Determining the mechanical efficiency of Otto engine's mechanism. Proceedings of the 9th IFToMM International Symposium on Theory of Machines and Mechanisms, (TMM' 05), Bucharest, Romania, pp: 141-146.

Petrescu, F.I. and R.V. Petrescu, 2013. Cinematics of the 3R Dyad. Engevista, 15: 118-124.

Petrescu, F.I.T. and R.V. Petrescu, 2012a. The Aviation History. Publisher: Books On Demand, ISBN-13: 978-3848230778.

Petrescu, F.I. and R.V. Petrescu, 2012b. MecatronicaSisteme Seriale si Paralele. Create Space Publisher, USA, ISBN-10: 978-1-4750-6613-5, pp: 128.

Petrescu, FIT., Petrescu RV., 2012c. Motoare Termice. Create Space publisher, 164 pages, ISBN-13: 9781480204881

Petrescu, F.I. and R.V. Petrescu, 2011. Mechanical Systems, Serial and Parallel-Course (in Romanian). LULU Publisher, London, UK, ISBN-10: 978-14466-0039-9, pp: 124.

Petrescu, F.I. and R.V. Petrescu, 2016a. Parallel moving mechanical systems kinematics, ENGEVISTA, 18: 455-491.

Petrescu, F.I. and R.V. Petrescu, 2016b. Direct and inverse kinematics to the Anthropomorphic Robots, ENGEVISTA, 18: 109-124.

Petrescu, F. and R. Petrescu, 2016c. An otto engine dynamic model. IJM\&P, 7: 038-048.

Petrescu, F.I. and R.V. Petrescu, 2016d. Otto motor dynamics. GEINTEC, 6: 3392-3406.
Petrescu, F.I. and R.V. Petrescu, 2016e. Dynamic cinematic to a structure 2R. GEINTEC, 6: 3143-3154.

Petrescu, F.I., B. Grecu, A. Comanescu and R.V. Petrescu, 2009. Some mechanical design elements. Proceeding of the International Conference on Computational Mechanics and Virtual Engineering, (MEC' 09), Braşov, pp: 520-525.

Petrescu, R.V., R. Aversa, A. Apicella, M.M. Mirsayar and F.I.T. Petrescu, 2016a. About the gear efficiency to a simple planetary train. Am. J. Applied Sci., 13: 1428-1436.

DOI: 10.3844/ajassp.2016.1428.1436

Petrescu, R.V., R. Aversa, A. Apicella, S. Li and G. Chen et al., 2016b. Something about electron dimension. Am. J. Applied Sci., 13: 1272-1276. DOI: 10.3844/ajassp.2016.1272.1276

Petrescu, F.I.T., A. Apicella, R. Aversa, R.V. Petrescu and J.K. Calautit et al., 2016c. Something about the mechanical moment of inertia. Am. J. Applied Sci., 13: $1085-1090$. DOI: 10.3844 /ajassp.2016.1085.1090

Petrescu, R.V., R. Aversa, A. Apicella, F. Berto and S. Li et al., 2016d. Ecosphere protection through green energy. Am. J. Applied Sci., 13: 1027-1032. DOI: 10.3844/ajassp.2016.1027.1032

Petrescu, F.I.T., A. Apicella, R.V. Petrescu, S.P. Kozaitis and R.B. Bucinell et al., 2016e. Environmental protection through nuclear energy. Am. J. Applied Sci., 13: 941-946. DOI: 10.3844/ajassp.2016.941.946

Petrescu, F.I.T. and J.K. Calautit, 2016a. About nano fusion and dynamic fusion. Am. J. Applied Sci., 13: 261-266. DOI: 10.3844/ajassp.2016.261.266

Petrescu, F.I.T. and J.K. Calautit, 2016b. About the light dimensions. Am. J. Applied Sci., 13: 321-325. DOI: 10.3844/ajassp.2016.321.325

Petrescu, R.V., R. Aversa, B. Akash, R. Bucinell and J. Corchado et al., 2017a. Modern propulsions for aerospace-a review. J. Aircraft Spacecraft Technol., 1: 1-8. DOI: 10.3844/jastsp.2017.1.8

Petrescu, R.V., R. Aversa, B. Akash, R. Bucinell and J. Corchado et al., 2017b. Modern propulsions for aerospace-part II. J. Aircraft Spacecraft Technol., 1: 9-17. DOI: 10.3844/jastsp.2017.9.17

Petrescu, R.V., R. Aversa, B. Akash, R. Bucinell and J. Corchado et al., 2017c. History of aviation-a short review. J. Aircraft Spacecraft Technol., 1: 30-49. DOI: $10.3844 /$ jastsp.2017.30.49

Petrescu, R.V., R. Aversa, B. Akash, R. Bucinell and J. Corchado et al., 2017d. Lockheed martin-a short review. J. Aircraft Spacecraft Technol., 1: 50-68. DOI: 10.3844/jastsp.2017.50.68

Petrescu, R.V., R. Aversa, B. Akash, J. Corchado and F. Berto et al., 2017e. Our universe. J. Aircraft Spacecraft Technol., 1: 69-79.

DOI: $10.3844 /$ jastsp.2017.69.79 
Petrescu, R.V., R. Aversa, B. Akash, J. Corchado and F. Berto et al., 2017f. What is a UFO? J. Aircraft Spacecraft Technol., 1: 80-90. DOI: 10.3844 /jastsp.2017.80.90

Petrescu, R.V., R. Aversa, B. Akash, J. Corchado and F. Berto et al., 2017g. About bell helicopter FCX-001 concept aircraft-a short review. J. Aircraft Spacecraft Technol., 1: 91-96. DOI: 10.3844 /jastsp.2017.91.96

Petrescu, R.V., R. Aversa, B. Akash, J. Corchado and F. Berto et al., 2017h. Home at airbus. J. Aircraft Spacecraft Technol., 1: 97-118. DOI: 10.3844 jastsp.2017.97.118

Petrescu, R.V., R. Aversa, B. Akash, J. Corchado and F. Berto et al., 2017i. Airlander. J. Aircraft Spacecraft Technol., 1: 119-148. DOI: $10.3844 /$ jastsp.2017.119.148

Petrescu, R.V., R. Aversa, B. Akash, J. Corchado and F. Berto et al., 2017j. When boeing is dreaming-a review. J. Aircraft Spacecraft Technol., 1: 149-161. DOI: 10.3844/jastsp.2017.149.161

Petrescu, R.V., R. Aversa, B. Akash, J. Corchado and F. Berto et al., 2017k. About Northrop Grumman. J. Aircraft Spacecraft Technol., 1: 162-185. DOI: $10.3844 /$ jastsp.2017.162.185

Petrescu, R.V., R. Aversa, B. Akash, J. Corchado and F. Berto et al., 20171. Some special aircraft. J. Aircraft Spacecraft Technol., 1: 186-203. DOI: $10.3844 /$ jastsp.2017.186.203

Petrescu, R.V., R. Aversa, B. Akash, J. Corchado and F. Berto et al., 2017m. About helicopters. J. Aircraft Spacecraft Technol., 1: 204-223. DOI: 10.3844 /jastsp.2017.204.223

Petrescu, R.V., R. Aversa, B. Akash, F. Berto and A. Apicella et al., 2017n. The modern flight. J. Aircraft Spacecraft Technol., 1: 224-233. DOI: 10.3844 /jastsp.2017.224.233

Petrescu, R.V., R. Aversa, B. Akash, F. Berto and A. Apicella et al., 2017o. Sustainable energy for aerospace vessels. J. Aircraft Spacecraft Technol., 1: 234-240. DOI: 10.3844/jastsp.2017.234.240

Petrescu, R.V., R. Aversa, B. Akash, F. Berto and A. Apicella et al., 2017p. Unmanned helicopters. J. Aircraft Spacecraft Technol., 1: 241-248. DOI: $10.3844 /$ jastsp.2017.241.248

Petrescu, R.V., R. Aversa, B. Akash, F. Berto and A. Apicella et al., 2017q. Project HARP. J. Aircraft Spacecraft Technol., 1: 249-257. DOI: 10.3844 /jastsp.2017.249.257

Petrescu, R.V., R. Aversa, B. Akash, F. Berto and A. Apicella et al., 2017r. Presentation of romanian engineers who contributed to the development of global aeronautics-part I. J. Aircraft Spacecraft Technol., 1: 258-271.

DOI: $10.3844 /$ jastsp.2017.258.271
Petrescu, R.V., R. Aversa, B. Akash, F. Berto and A. Apicella et al., 2017s. A first-class ticket to the planet mars, please. J. Aircraft Spacecraft Technol., 1: 272-281.

DOI: 10.3844/jastsp.2017.272.281

Petrescu, R.V., R. Aversa, B. Akash, F. Berto and A. Apicella et al., 2017t. Forces of a 3R robot. J. Mechatronics Robotics, 1: 1-14. DOI: $10.3844 /$ jmrsp.2017.1.14

Petrescu, R.V., R. Aversa, B. Akash, F. Berto and A. Apicella et al., 2017u. Direct geometry and cinematic to the MP-3R systems. J. Mechatronics Robotics, 1: 15-23.

DOI: $10.3844 / j m r s p .2017 .15 .23$

Petrescu, R.V., R. Aversa, B. Akash, F. Berto and A. Apicella et al., 2017v. Dynamic elements at MP3R. J. Mechatronics Robotics, 1: 24-37. DOI: $10.3844 / j m r s p .2017 .24 .37$

Petrescu, R.V., R. Aversa, B. Akash, F. Berto and A. Apicella et al., 2017w. Geometry and direct kinematics to MP3R with $4 \times 4$ operators. J. Mechatronics Robotics, 1: 38-46. DOI: $10.3844 / \mathrm{jmrsp} .2017 .38 .46$

Petrescu, R.V., R. Aversa, A. Apicella, M.M. Mirsayar and S. Kozaitis et al., 2017x. Current stage in the field of mechanisms with gears and rods. J. Mechatronics Robotics, 1: 47-57. DOI: $10.3844 /$ jmrsp.2017.47.57

Petrescu, R.V., R. Aversa, A. Apicella, M.M. Mirsayar and S. Kozaitis et al., 2017y. Geometry and inverse kinematic at the MP3R mobile systems. J. Mechatronics Robotics, 1: 58-65. DOI: $10.3844 / \mathrm{jmrsp} .2017 .58 .65$

Petrescu, R.V., R. Aversa, A. Apicella, M.M. Mirsayar and S. Kozaitis et al., 2017z. Synthesis of optimal trajectories with functions control at the level of the kinematic drive couplings. J. Mechatronics Robotics, 1: 66-74.

DOI: $10.3844 /$ jmrsp.2017.66.74

Petrescu, R.V., R. Aversa, A. Apicella, M.M. Mirsayar and S. Kozaitis et al., 2017aa. The inverse kinematics of the plane system 2-3 in a mechatronic MP2R system, by a trigonometric method. J. Mechatronics Robotics, 1: 75-87. DOI: $10.3844 /$ jmrsp.2017.75.87

Petrescu, R.V., R. Aversa, A. Apicella, M.M. Mirsayar and S. Kozaitis et al., 2017ab. Serial, anthropomorphic, spatial, mechatronic systems can be studied more simply in a plan. J. Mechatronics Robotics, 1: 88-97. DOI: 10.3844/jmrsp.2017.88.97

Petrescu, R.V., R. Aversa, A. Apicella, M.M. Mirsayar and S. Kozaitis et al., 2017ac. Analysis and synthesis of mechanisms with bars and gears used in robots and manipulators. J. Mechatronics Robotics, 1: 98-108.

DOI: $10.3844 /$ jmrsp.2017.98.108 
Petrescu, R.V., R. Aversa, A. Apicella, M.M. Mirsayar and S. Kozaitis et al., 2017ad. Speeds and accelerations in direct kinematics to the MP3R systems. J. Mechatronics Robotics, 1: 109-117. DOI: $10.3844 /$ jmrsp.2017.109.117

Petrescu, R.V., R. Aversa, A. Apicella, M.M. Mirsayar and S. Kozaitis et al., 2017ae. Geometry and determining the positions of a plan transporter manipulator. J. Mechatronics Robotics, 1: 118-126. DOI: $10.3844 /$ jmrsp.2017.118.126

Petrescu, F.I.T., 2008. Theoretical and applied contributions about the dynamic of planar mechanisms with superior linkages. Ph.D. Thesis.

Reddy, P., K.V. Shihabudheen and J. Jacob, 2012. Precise non linear modeling of flexible link flexible joint manipulator. IReMoS, 5: 1368-1374.

Sava, I., 1970. Contributions to the optimum dynamics and synthesis of cams mechanisms. PhD Thesis, I.P.B.

Sava, I., 1971. Regarding the dynamic functioning of the internal combustion engine valve control valve. C.M. No.12., Bucharest.

Sevil, H.E. and A. Dogan, 2015. Fault diagnosis in air data sensors for receiver aircraft in aerial refueling. J. Guidance Control Dynam., 38: 1959-1975. DOI: 10.2514/1.G000527

Sherson, J.F., H. Krauter, RK. Olsson, B. Julsgaard and K. Hammerer et al., 2006. Quantum teleportation between light and matter. Nature, 443: 557-560. DOI: 10.1038 /nature 05136

Sun, J.Z. and S.M. Joshi, 2009. An indirect adaptive control scheme in the presence of actuator and sensor failures. Proceedings of the AIAA Guidance, Navigation and Control Conference, Aug. 10-13, Chicago, Illinois. DOI: 10.2514/6.2009-5740

Tabaković, S., M. Zeljković, R. Gatalo and A. $\mathrm{Z} \square$ ivković, 2013. Program suite for conceptual designing of parallel mechanism-based robots and machine tools. Int. J. Adv. Robot Sys.

DOI: $10.5772 / 56633$
Tang, X., D. Sun and Z. Shao, 2013. The structure and dimensional design of a reconfigurable PKM. IJARS. DOI: $10.5772 / 54696$

Tesar, D. and G.K. Matthew, 1974. The design of modelled cam sistems. In cams and cam mechanisms.

The Future of Aircraft Propulsion is Electric | NASA. https:/www.nasa.gov/centers/armstrong/Features/le aptech.html

Tong, G., J. Gu and W. Xie, 2013. Virtual entity-based rapid prototype for design and simulation of humanoid robots. Int. J. Adv. Robot. Sys. DOI: $10.5772 / 55936$

Venkataraman, G., 1992. Chandrasekhar and his Limit. 1 st Edn., Universities Press, ISBN-10: 817371035X, pp: 89.

Wang, K., M. Luo, T. Mei, J. Zhao and Y. Cao, 2013. Dynamics analysis of a three-DOF planar serialparallel mechanism for active dynamic balancing with respect to a given trajectory. Int. J. Adv. Robotic Sys. DOI: 10.5772/54201

Wiederrich, J.L. and B. Roth, 1974. Design of Low Vibration Cam Profiles. In: Cams and Cam Mechanisms, Rees Jones, J. (Ed.), London and Birmingham, Alabama.

Williams, D.R., 1995. Saturnian satellite fact sheet. NASA. https://nssdc.gsfc.nasa.gov/planetary/factsheet/satur niansatfact.html

Wen, S., J. Zhu, X. Li, A. Rad and X. Chen, 2012. Endpoint contact force control with quantitative feedback theory for mobile robots. IJARS.

DOI: $10.5772 / 53742$

\section{Source of Figures}

Petrescu and Petrescu, 2012c. 